\title{
How will mosquitoes adapt to climate change?
}

\author{
Lisa Couper ${ }^{1}$, Johannah Farner ${ }^{1}$, Jamie Caldwell ${ }^{1}$, Marissa Childs ${ }^{1}$, Mallory Harris ${ }^{1}$, Devin \\ Kirk $^{1}$, Nicole Nova ${ }^{1}$, Marta Shocket ${ }^{1}$, Eloise Skinner ${ }^{1}$, Lawrence Uricchio ${ }^{2}$, Moises \\ Exposito-Alonso ${ }^{3}$, and Erin Mordecai ${ }^{1}$ \\ ${ }^{1}$ Stanford University \\ ${ }^{2}$ University of California Berkeley \\ ${ }^{3}$ Carnegie Institution for Science Department of Plant Biology
}

November 20, 2020

\begin{abstract}
Accurately predicting and mitigating the effects of climate change on species ranges and interactions is a critical challenge. In particular, mosquito-borne diseases like malaria and dengue are poised to shift with climate change. Understanding this impact hinges on a key open question: How will mosquitoes adapt to climate change? Here we adapt a simple framework widely used in conservation biology - evolutionary rescue models - to investigate the potential for mosquito climate adaptation, and we synthesize current evidence, focusing on adaptation to rising temperatures. Short mosquito generation times, high population growth rates, and strong temperature-imposed selection favor mosquito thermal adaptation. However, knowledge gaps about the extent of phenotypic and genotypic variation in thermal tolerance within mosquito populations, the environmental sensitivity of selection, and the role of phenotypic plasticity constrain our ability to make more precise estimates. Future research efforts should prioritize filling these data gaps. Specifically, we outline how common garden and selection experiments can be used to this end. Collecting and incorporating these data into an evolutionary rescue framework will improve estimates of mosquito adaptive potential and of changes in mosquito-borne disease transmission under climate change, and this approach can be applied more broadly to pests as well as species of conservation concern.
\end{abstract}

Article title: How will mosquitoes adapt to climate change?

Authors: Lisa I. Couper ${ }^{1}$, Johannah E. Farner ${ }^{1}$, Jamie M. Caldwell ${ }^{1,2,3}$, Marissa L. Childs ${ }^{4}$, Mallory J. Harris $^{1}$, Devin G. Kirk ${ }^{1,5}$, Nicole Nova ${ }^{1}$, Marta S. Shocket ${ }^{1,6}$, Eloise B. Skinner ${ }^{1,7}$, Lawrence H. Uricchio ${ }^{8}$, Moises Exposito-Alonso ${ }^{1,9}$, Erin A. Mordecai ${ }^{1}$

Author affiliations:

${ }^{1}$ Department of Biology, Stanford University, Stanford, CA, USA

${ }^{2}$ Hawai'i Institute of Marine Biology, University of Hawai‘i at Mānoa, Kāne'ohe, HI, USA

${ }^{3}$ ARC Centre of Excellence for Coral Reef Studies, James Cook University, Townsville, Qld, Australia

${ }^{4}$ Emmett Interdisciplinary Program in Environment and Resources, Stanford University, Stanford, CA, USA

${ }^{5}$ Department of Zoology, University of Toronto, Toronto, Canada

${ }^{6}$ Department of Ecology and Evolutionary Biology, University of California Los Angeles, Los Angeles, USA

${ }^{7}$ Environmental Futures Research Institute, Griffith University, Brisbane, Australia

${ }^{8}$ Department of Integrative Biology, University of California, Berkeley, Berkeley, CA, USA 
${ }^{9}$ Department of Plant Biology, Carnegie Institution for Science, Stanford, CA, USA

\section{Corresponding author:}

Lisa Couper

lcouper@stanford.edu

327 Campus Drive, Stanford CA, 94305

Type of article: Ideas and Perspectives

Short running title: Mosquito climate adaptation

Key words: climate change, adaptation, mosquito, vector, evolutionary rescue, thermal tolerance

Abstract word count: 202

Main text word count: 6,403

Text Box 1 word count: 232

Number of figures, tables, and textboxes : 3 total (2 figures, 0 tables, 1 textbox)

Statement of authorship: LIC, JEF, and EAM conceived of the project. All authors contributed to the conceptual design, literature review, and writing. MSS performed analysis for Table S2. LIC and JEF wrote the first draft of the manuscript, and all authors contributed substantially to revisions.

Data accessibility statement: All data supporting the results will be archived in Dryad and the data DOI will be included at the end of the article.

\section{Abstract}

Accurately predicting and mitigating the effects of climate change on species ranges and interactions is a critical challenge. In particular, mosquito-borne diseases like malaria and dengue are poised to shift with climate change. Understanding this impact hinges on a key open question: How will mosquitoes adapt to climate change? Here we adapt a simple framework widely used in conservation biology-evolutionary rescue models - to investigate the potential for mosquito climate adaptation, and we synthesize current evidence, focusing on adaptation to rising temperatures. Short mosquito generation times, high population growth rates, and strong temperature-imposed selection favor mosquito thermal adaptation. However, knowledge gaps about the extent of phenotypic and genotypic variation in thermal tolerance within mosquito populations, the environmental sensitivity of selection, and the role of phenotypic plasticity constrain our ability to make more precise estimates. Future research efforts should prioritize filling these data gaps. Specifically, we outline how common garden and selection experiments can be used to this end. Collecting and incorporating these data into an evolutionary rescue framework will improve estimates of mosquito adaptive potential and of changes in mosquito-borne disease transmission under climate change, and this approach can be applied more broadly to pests as well as species of conservation concern.

Introduction

The potential for adaptive evolution to enable species persistence under a changing climate is one of the most important questions for understanding future climate change impacts (Lavergne et al. 2010). Evolutionary change on ecological time scales (tens of generations) has been documented across a wide range of taxa, suggesting that some species could adapt as quickly as the climate is changing (reviewed in Thompson 1998, Hairston et al. 2005, Carroll et al. 2007, Reznick et al. 2019). Evidence of evolutionary adaptation to contemporary climate change is more limited, but has emerged for diverse taxa including mammals (Réale et al. 2003), fish (Kovach et al. 2012), plants (Franks et al. 2007, Exposito-Alonso et al. 2018), birds (Nussey et al. 2005, Karell et al. 2011), and insects (Umina et al. 2005). However, while climate adaptation has typically been studied in the context of conservation biology, population genetics theory suggests that evolutionary climate adaptation is more likely for short-lived species with large population sizes-properties of many pest 
species, including disease vector species (Lynch and Lande 1993, Bürger and Lynch 1995). For these pest and vector species, the unknown potential for climate adaptation threatens human health and well-being.

Mosquito-borne diseases are a major public health burden, causing an estimated 500 million cases and millions of deaths globally each year (World Health Organization 2014, 2018). Studies of how environmental conditions influence mosquito-borne disease risk highlight temperature - and by extension, climate warmingas an important driver of transmission dynamics (Shragai et al. 2017, Mordecai et al. 2019, Franklinos et al. 2019). Temperature influences mosquito-borne disease dynamics because it directly affects mosquito physiology, life cycles, behavior, and competence for disease transmission (Cator et al. 2020). For mosquitoes, as with other ectotherms, temperature has strong, nonlinear effects on traits such as survival and fecundity that lead to unimodal effects on fitness, where temperatures above and below intermediate thermal optima suppress mosquito population growth (Huey and Stevenson 1979, Huey and Berrigan 2001, Angilletta 2009, Amarasekare and Savage 2012). Recent forecasts based on this relationship predict that in some areas where disease risk is currently high, future risk will decrease as temperatures exceed mosquito thermal optima and limits (Gething et al. 2010, Ryan et al. 2015, 2019, Mordecai et al. 2019, 2020). However, if mosquitoes adapt to climate warming by increasing their thermal tolerance, then these predictions are likely to underestimate future disease risk.

Recent research demonstrates the potential for mosquito climate adaptation within a few decades. For example, multiple lines of evidence indicate that the invasive Asian tiger mosquito (Aedes albopictus ) responds to novel temperature conditions within 10 - 30 years of population expansions into new locations. Putative adaptive responses observed on this timescale include altered allele frequencies, thermal niche shifts reflecting greater cold tolerance, and photoperiod responses that influence overwintering survival (Medley 2010, Urbanski et al. 2012, Egizi et al. 2015, Medley et al. 2019). Similarly, genetically based shifts in photoperiod towards shorter, more southern daylengths in association with recent warming occurred in as little as five years in the pitcher-plant mosquito (Wyeomyia smithii ) (Bradshaw and Holzapfel 2001). While these examples cover just two species, and do not provide precise evidence for the pace of thermal adaptation in response to climate warming, they indicate that there is potential for rapid climate adaptation in mosquitoes.

Here, we take advantage of substantial recent research progress on mosquito thermal biology (reviewed in Mordecai et al. 2019) and the impact of temperature change on mosquito-borne disease (reviewed in Andriamifidy et al. 2019, Franklinos et al. 2019) to address a key open question: How will mosquitoes adapt to climate change? We provide a theoretical framework for addressing this question and synthesize direct and indirect evidence of mosquito climate adaptation. In the following sections, we 1) outline how to investigate mosquito adaptive potential, positing evolutionary rescue models as a guiding framework, 2) synthesize evidence and identify key data gaps for predictive modeling, and 3) highlight priorities and approaches for filling these gaps. We discuss the adaptive potential of mosquitoes broadly, but our principal interest is in major disease vector species (e.g., Aedes aegypti, Ae. albopictus, Anopheles gambiae, Culex pipiens, Cx. quinquefasciatus, which transmit dengue, chikungunya, Zika, and West Nile viruses, malaria, and other pathogens) and we discuss species-specific responses where possible. We focus here on adaptation to warming temperatures that exceed current mosquito thermal optima, but the approach we describe can be applied to study the adaptive potential of any species in response to any specific environmental change.

Framework for investigating climate adaptation

Mosquitoes may respond to warming temperatures through three primary mechanisms: tracking suitable temperatures through range shifts, avoiding or temporarily coping with stressful temperatures through phenotypic plasticity, and tolerating warming through evolutionary adaptation. Here we focus on evolutionary adaptation as it would enablein situ mosquito population persistence under sustained environmental change and is currently the least well-understood climate response (Merilä and Hendry 2014, Urban et al. 2016). Investigating the potential for evolutionary climate adaptation requires identifying: 1) the climate factors currently limiting population persistence, 2) the most climate-sensitive and fitness-relevant traits, and 3) the potential evolutionary rates of these traits (Figure 1). 


\section{Climate factors currently limiting population persistence}

Temperature fundamentally limits mosquito ranges and persistence through its influence on mosquito survival, development, and reproductive rates, but the precise aspects of temperature that determine these limits remain unclear (Christophers 1960, Yang et al. 2009, Brady et al. 2013, Shapiro et al. 2017, Tesla et al. 2018, Shocket et al. 2018, Mordecai et al. 2019). Temperature averages, variability, extremes, and interactions among these factors all impact ectotherm fitness (Lambrechts et al. 2011, Bozinovic et al. 2011, Kingsolver et al. 2013, Paaijmans et al. 2013, Blanford et al. 2013, Dowd et al. 2015, Buckley and Huey 2016). While the temperature variable that most strongly constrains mosquito persistence will likely vary by location and population, maximum temperature has been identified as the strongest driver of species extinctions across a wide range of animal and plant species (Román-Palacios and Wiens 2020). Because environmental temperatures that exceed organismal thermal optima or critical thermal maxima have especially strong negative impacts on fitness (Deutsch et al. 2008, Kingsolver et al. 2013), changes in maximum summer temperatures may exert the strongest selection pressure on mosquito populations near their warm range limits. As most temperature - trait responses are studied under constant temperatures (Deutsch et al. 2008, Angilletta 2009, Paaijmans et al. 2013, Vasseur et al. 2014, Dowd et al. 2015, Buckley and Huey 2016), we consider mosquito responses to increases in mean temperature as a focal example. However, the framework we present can readily be applied to any specific measure of temperature or other environmental variable, such as temperature extremes, precipitation, wind patterns, land use change, and human activities (Reiter 2001, Patz et al. 2008, Paaijmans and Thomas 2011, Mordecai et al. 2019, Franklinos et al. 2019, Rocklöv and Dubrow 2020).

\section{Mosquito traits}

As selection acts on specific phenotypes, 'adaptation' here refers to a change in the thermal tolerance of a specific mosquito trait-an emergent property that reflects underlying changes in the thermal sensitivity of proteins (Somero 1995, 2003, 2010). The critical traits to examine are those with the strongest climate sensitivity and the strongest impact on overall mosquito fitness. We hypothesize that warming temperatures will impose the strongest selection pressure on traits with the lowest thermal optima and critical thermal maxima. For many mosquito species, these traits are adult lifespan and immature survival (reviewed in Mordecai et al. 2019). However, whether these traits also pose the strongest constraints on mosquito fitness and persistence at high temperatures remains poorly understood because prior work has largely focused on mosquito traits related to disease transmission during the activity season, but there may be additional traits that help mosquitoes tolerate thermal extremes. For this reason, we consider several fitness-relevant mosquito life history traits (e.g., survival, development rates, and fecundity). Additionally, we consider various metrics that describe trait thermal tolerance (e.g., time to partial paralysis, known as 'knockdown time' at high temperatures, trait performances at high temperatures, and temperatures causing $50 \%$ sample mortality) because they may provide differing information on species adaptive potential (Hangartner and Hoffmann 2016). The framework outlined here can be applied to any specific trait and measurement.

\section{Potential evolutionary rates of climate-sensitive traits}

After identifying the climate factors and mosquito traits that limit population persistence, we can now compare their rates of change to predict whether populations can adapt apace with environmental change. To do so, we turn to evolutionary rescue models, which estimate the maximum rate of evolutionary change (i.e., adaptive genetic turnover) of a population and compare it to the projected rate of environmental change. Populations can persist only when their maximum sustainable evolutionary rate exceeds the required rate of evolution dictated by the environment (Bell and Gonzalez 2009, Hoffmann and Sgrò 2011, Gomulkiewicz and Shaw 2013, Gonzalez et al. 2013, Carlson et al. 2014, Bell 2017). Evolutionary rescue models explicitly model demographic rates and assume that populations are comprised of different genotypes with different reproductive advantages. As these models track population responses to sustained, directional environmental change, they are well-suited to estimating the potential for thermal adaptation in response to climate warming (Huey and Kingsolver 1993, Bürger and Lynch 1995, Chevin et al. 2010, Bay et al. 2017, Cotto et al. 2017, Diniz-Filho et al. 2019), and have provided valuable estimates of climate adaptation potential across a range of taxa (Gienapp et al. 2013, Cotto et al. 2017, Diniz-Filho et al. 2019). Even with incomplete or imprecise 
knowledge of all parameters, these models can place bounds on the climate response space to indicate where adaptation is highly unlikely and to inform future data collection efforts.

Here, we consider the analytic, quantitative-genetic evolutionary rescue model described by Chevin et al. (2010). This model estimates population adaptive potential under climate warming using (Box 1): 1) the maximum population growth rate under optimal conditions, 2) the population generation time, 3) the phenotypic variance in the trait of interest, 4) the strength of selection imposed by temperature change, 5) the trait heritability, 6) the degree of phenotypic plasticity in thermal tolerance, 7) how the trait optimum changes with temperature (i.e., environmental sensitivity of selection), and 8) the expected rate of temperature change during the time period. Although the simplicity of this analytic evolutionary rescue model may constrain the accuracy of its projections, it illustrates the basic factors likely to affect population persistence, which we consider to be the minimum information needed to make initial predictions (see Supporting Information Appendix A for additional unmodeled factors and the Discussion for methods to incorporate additional complexity). We present the main findings below, including information from the closely related model organismDrosophila when little information is available for mosquitoes.

Estimating evolutionary rates

\section{Generation time and maximum population growth rate}

Short generation times enable rapid evolutionary responses (Lynch and Lande 1993, Burger and Lynch 1995), and high intrinsic population growth rates reduce the chance of extinction prior to adaptation (Burger and Lynch 1995, Orr and Unckless 2008, Gomulkiewicz and Houle 2009). The generally rapid life cycles and large population sizes of mosquitoes favor rapid evolution, but precise demographic estimates under natural conditions are unavailable for most species (but see Appendix C: Table S2) and will vary with biotic and abiotic conditions. However, even high estimates of mosquito lifespans of approximately three months (Macdonald 1952, Nayar and Sauerlllan 1971, Papadopoulos et al. 2016, Joubert et al. 2016) are on par with or well below those of other species that have already demonstrated evolutionary responses to climate change (Rodriguez-Trelles and Rodriguez 1998, Reale et al. 2003, Balanya et al. 2006, Franks et al. 2007, Gienapp et al. 2007, Ożgo and Schilthuizen 2012, Kovach et al. 2012). Further, high intrinsic population growth rates (r) of $0.19-0.38$ per generation have been calculated for several major vector species (Appendix C: Table S2, Figure S1; Amarasekare and Savage 2012, Johnson et al. 2015, Mordecai et al. 2017, Shocket et al. 2020) and census population size estimates on the order of 1,000 - 10,000 individuals have been found across studies of varying mosquito species and settings (Touré et al. 1998, Lehmann et al. 1998, Macielde-Freitas et al. 2008, Neira et al. 2014, Le Goff et al. 2019). Placing these mosquito results in context, a Drosophila modeling study showed that growth rates and population sizes in this range facilitated population persistence for over 300 generations under heat-knockdown selection (Willi and Hoffmann 2009). Mosquito demographic characteristics therefore favor thermal adaptation.

\section{Variation in thermal tolerance}

Higher genetically based variance in a trait results in higher rates of phenotypic evolution (Lande 1976). While no studies (to our knowledge) have measured within-population variation in mosquito thermal tolerance, several studies have investigated variation between populations (Mogi 1992, Reisen 1995, Dodson et al. 2012, Vorhees et al. 2013, Ruybal et al. 2016, Chu et al. 2019). Overall, these studies find genetically based, but often trait-specific variation that did not always clearly support local thermal adaptation (i.e., a correlation between trait values and local climatic conditions; Appendix C: Table S1). For example, some studies have found thermal tolerance varying predictably with the population's thermal environment of origin-upper thermal limits of mosquito respiration and survival after heat shock were positively correlated with the temperature of origin for Cx. tarsalis and An. gambiae, respectively (Rocca et al. 2009, Vorhees et al. 2013). However, several other studies have found the opposite pattern (Ruybal et al. 2016), found minimal or no variation in thermal responses between populations (Dodson et al. 2012, Mogi et al. 1992), or found that certain populations had uniformly higher or lower trait performance at all experimental temperatures independent of their climate of origin (Ruybal et al. 2016, Reisen et al. 1995, Chu et al. 2019, Dodson et al. 
2012). Taken together, mosquito populations do sometimes vary in their thermal performance, but there is no clear evidence for existing local thermal adaptation across temperature gradients of similar magnitude to those predicted by climate change over the next several decades. This suggests either barriers to thermal adaptation or relatively weak selection on thermal performance (see 'Strength of selection' section). However, the lack of within-population sampling and/or idiosyncratic, trait-specific temperature relationships may have obscured true patterns of local adaptation (Bradshaw et al. 2000).

\section{Heritability of thermal tolerance}

Higher heritability - the proportion of phenotypic variance in a population attributable to genetic effectsenables faster evolutionary rates because populations respond more efficiently to selection (Falconer and Mackay 1996). To our knowledge, there are no estimates of the heritability of trait thermal tolerance for mosquitoes. However, evolutionary theory and empirical work in other systems suggest that thermal tolerance heritability is generally low. In particular, highly polygenic, complex, or environmentally-dependent traits-as expected for thermal tolerances - typically have low heritability (Bay et al. 2017). Supporting this expectation, a meta-analysis of heritability data for upper thermal limits in Drosophila resulted in an overall estimate of 0.28 (i.e., $28 \%$ of the populations phenotypic variance is due to genetic variance; Diamond 2017), which is similar to heritability estimates for other Drosophila life history traits (average $\mathrm{h}^{2}=0.26$; Roff and Mousseau 1987, Mousseau and Roff 1987) and indicates moderately low heritability. However, more recent evidence suggests Drosophila can rapidly adapt to novel temperatures through multiple, alternative genetic pathways that lead to similar increases in thermal tolerance (i.e, 'genetic redundancy'), challenging the notion that highly polygenic traits have low heritability (Barghi et al. 2019). In general, uncertainty surrounding the ecological relevance of laboratory measurements of insect thermal tolerance (Terblanche et al. 2007, Chown et al. 2009, Mitchell and Hoffmann 2010) and the divergent evolutionary histories of Drosopholids and mosquitoes limit our understanding of thermal tolerance trait heritability in mosquitoes.

\section{Strength of selection}

Given non-zero heritability, stronger natural selection-the differential survival or reproduction of mosquitoes with different trait values - would lead to faster adaptive responses, despite causing high initial mortality (Lynch and Lande 1993, Hartl and Clark 1997). Temperature-imposed selection on mosquitoes, which can be approximated from temperature-dependent survival rates (Box 1, $\gamma$; Falconer and Mackay 1996), is likely to be strong. Upper thermal limits for adult and larval survival are as low as $32-38^{\circ} \mathrm{C}$ (reviewed in Mordecai et al. 2019), which many mosquito populations - particularly those in the tropics-already experience and will increasingly face in a warming climate (Deutsch et al. 2008). Further, steep declines in survival between thermal optima and critical limits have been observed across mosquito species (Focks et al. 1993, Alto and Juliano 2001, Kamimura et al. 2002, Delatte et al. 2009, Muturi et al. 2011, Mordecai et al. 2019). This high selection pressure may facilitate mosquito adaptation, provided that heritable variation in trait thermal tolerance exists.

\section{Phenotypic plasticity}

Phenotypic plasticity-the ability of individual genotypes to produce varying phenotypes based on the environment (West-Eberhard 2003)-provides an alternative mechanism for coping with climate change that is more rapid than evolutionary adaptation. However, because plasticity impedes natural selection on genetically based variation, it may ultimately inhibit population persistence under long-term directional change (Gienapp et al. 2008, Whitman and Agrawal 2009, Chevin et al. 2010, 2013, Merilä and Hendry 2014). For mosquitoes, potentially important plastic responses include changes in activity patterns, biting behavior, or microhabitat selection, thermal acclimation, and initiation of dormancy, as reviewed below (and see Appendix C: Table S3). Phenotypic plasticity may itself vary across genotypes and thus could evolve in response to environmental change, but experimental evidence that this is possible is lacking (DeWitt et al. 1998, Scheiner and Berrigan 1998, Stinchcombe et al. 2004). Overall, mosquitoes possess a variety of potential plastic responses, but the capacity for these responses to increase thermal tolerance, their potential fitness costs, and how these plastic responses might interact with the process of evolutionary adaptation remain 
poorly understood. Below, we review current knowledge of different potential plastic responses.

\section{Behavioral thermoregulation}

Mosquito behavioral avoidance of high temperatures, particularly to short-term temperature extremes, can temporarily enable persistence in warming habitats. Several studies have shown shifts in the biting time or habitat selection of mosquitoes, particularly An. gambiae, seasonally or in response to insecticide spraying (Taylor 1975, Reisen and Aslamkhan 1978, Voorham 2002, Pates and Curtis 2005, Manda et al. 2011). While such behavioral shifts have not been conclusively linked to temperature, studies have found increasing usage of underground or shaded oviposition sites that was correlated with increasing temperature, and not associated with change in habitat availability or accompanied by genetic differentiation (Ae. aegypti, Somers et al. 2011, Chadee and Martinez 2016). Seeking out and accessing cooler microclimates may buffer mosquitoes from warm temperature extremes, reducing mortality and decreasing the strength of selection. However, evidence for mosquito behavioral thermoregulation more generally remains limited (Paaijmans and Thomas 2011, Waldock et al. 2013), and trade-offs in resource acquisition from restricted foraging and activity time, and a lack of readily available cooler microhabitats would constrain this behavior (Angilletta 2009, Sears et al. 2016, Huey and Kingsolver 2019). Conversely, the absence of evidence for this phenomenon may be due to measurement challenges associated with observing mosquitoes in the field (Paaijmans and Thomas 2011).

\section{Thermal acclimation}

Increases in thermal tolerance after exposure to warmer temperatures during development-a form of thermal acclimation-have been documented in several mosquito species (An. albimanus, Benedict et al. 1991; An. arabiensis and An. funestus, Lyons et al. 2012; Cx. pipiens, Gray 2013; Ae. aegypti, Sivan et al. 2020). However, increases in thermal limits were typically minimal, suggesting a limited capacity for thermal acclimation to reduce mortality at high temperatures and enable population persistence. For example, the critical thermal limits of respirometry, motor function, or survival increased by less than $2^{\circ} \mathrm{C}$ for populations developing in $5^{\circ} \mathrm{C}$ warmer environments (Benedict et al. 1991, Lyons et al. 2012, Gray 2013). Similarly, critical thermal maxima varied minimally with acclimation temperatures across a diverse range of over 200 ectotherm species (Gunderson and Stillman 2015, Somero et al. 2016, van Heerwaarden et al. 2016, Rohr et al. 2018).

\section{Dormancy}

Temporarily unfavorable environmental conditions could be overcome through dormancy-the interruption or reduction of metabolic activity through diapause or quiescence - a response that has been demonstrated in all major vector species (reviewed in Diniz et al. 2017). Dry-season dormancy (i.e., aestivation) is likely one mechanism enabling An. gambiae and An. coluzzi to persist during the three- to six-month long dry season in the Sahel, as evidenced by very low population sizes during the dry season followed by rapid increases after the first rain (Lehmann et al. 2010, 2014, Adamou et al. 2011, Yaro et al. 2012, Dao et al. 2014). However, there are no known examples of dormancy mechanisms in ectotherms that respond solely to high temperatures, thus this may be an unlikely response for mosquitoes, particularly tropical species facing warming temperatures in humid environments.

\section{Environmental sensitivity of selection}

Environmental sensitivity of selection refers to how the optimum phenotype shifts with changes in the environment and is typically measured as the slope of the relationship between the optimal trait value and the environmental variable (e.g., the rate of change in the optimal upper thermal limit of adult life span against maximum summer temperature; Chevin et al. 2010, 2015). A larger difference between the environmental sensitivity of selection and phenotypic plasticity (i.e., a greater deviation in the phenotype from the optimal value) necessitates faster adaptation (Chevin et al. 2010). For mosquitoes, as for nearly all other organisms, the environmental sensitivity of trait thermal tolerance has not been empirically measured (Chevin et al. 2010). However, across mosquito populations (Lyons et al. 2012, Vorhees et al. 2013) and species (Mordecai et al. 2019), upper thermal limits for most mosquito life history traits were less variable 
than lower thermal limits and optima. These patterns could reflect strong environmental sensitivity on lower thermal tolerance, intermediate sensitivity for the optimum, and weak sensitivity on upper thermal tolerance. However, it may more likely reflect evolutionary constraints on upper thermal tolerance (Kellermann et al. 2012, Hoffmann et al. 2013), or result from competing selection pressures, genetic constraints, or gene flow hindering thermal adaptation (Angilletta 2009).

\section{Expected rate of environmental change}

Rates of environmental change will vary based on the specific temperature variable being considered (e.g., mean temperature of the hottest month or quarter, maximum temperature in the dry season, etc.), and depend on climate policy: projections of global mean annual surface temperatures in 2100 vary by over $3^{\circ} \mathrm{C}$ depending on the future climate scenario (Collins et al. 2013). However, while greater warming is projected for higher latitudes (IPCC 2007), faster rates of adaptation may be necessary for tropical mosquito species such as An. gambiae, Ae. aegypti, and Ae. albopictus that already experience environmental temperatures close to their thermal optima and may experience large fitness costs under additional warming in the absence of adaptation (Deutsch et al. 2008, Somero 2010, Ryan et al. 2015, 2019, Mordecai et al. 2019).

Priorities and approaches for measuring adaptive potential

Addressing several key data and knowledge gaps will improve our ability to estimate mosquito adaptive potential. As outlined above, there are virtually no estimates of the heritability of thermal tolerance traits, environmental sensitivity of selection, and within-population variation (and few estimates of between-population variation) in thermal tolerance for mosquitoes specifically. Additionally, we have a limited understanding of the role of phenotypic plasticity, particularly behavioral thermoregulation, in mosquito thermal tolerance. Although other parameters of the evolutionary rescue model, including the strength of selection imposed by temperature change, mosquito generation time, and maximum population growth rate, are often not measured directly or precisely, we have relatively more information about these parameters and they are unlikely to be the primary constraints on evolutionary adaptation (see 'Estimating evolutionary rates'). We therefore recommend that future research focus on measuring environmental sensitivity of selection, plasticity, and within-population variation and heritability in thermal tolerance. We discuss the most promising and feasible approaches for doing so below.

Selection experiments are a powerful tool for investigating the evolution of complex traits (reviewed in Fuller et al. 2005, Garland and Rose 2009, Swallow et al. 2009) that can be used to estimate several of the parameters in evolutionary rescue model parameters. In artificial selection experiments, where individuals are chosen to advance to the next generation based on their value for a particular trait (e.g., time to thermal knockdown), heritability can be measured as: $h^{2}=R /\left(i \sigma_{p}\right)$ (Falconer and Mackay 1996). Here, $R$ is the mean difference in the trait between control and selected lines, $\sigma_{p}$ is the trait standard deviation in the control lines, and $i$, the intensity of selection, is determined based on what proportion of the population is selected each generation (see Box 1). In laboratory natural selection-in which the treatments, rather than the researcher, impose the selection pressure-selection strength itself can be approximated based on the survival rates between generations held at specific temperatures (see Box 1). Both selection designs have been used extensively with model organisms such asDrosophila spp., Daphnia spp., and Escherichia colito measure changes in upper limits of trait thermal tolerance. While no thermal selection experiments have yet been published on mosquitoes (Dennington et al., in prep), several major vector species, including Ae. aegypti and Cx. quinquefasciatus, can be readily maintained and manipulated in the lab (Munstermann 1997, Kauffman et al. 2017) and can therefore be used in experiments to obtain estimates of the heritability of thermal tolerance and the selection strength imposed by different temperature conditions.

Common garden experiments, where traits are measured for distinct populations or genotypes exposed to the same environmental conditions, enable measurement of nearly all rescue model parameters (Clausen et al. 1941, Merilä and Hendry 2014, Villemereuil et al. 2016, Berend et al. 2019). In mosquitoes, common garden experiments have been used to investigate variation in thermal tolerance between populations sampled across a thermal gradient (Mogi 1992, Reisen 1995, Rocca et al. 2009, Vorhees et al. 2013, Ruybal et al. 2016, Chu 
et al. 2019), but this approach could also be used to measure within-population variation if thermal tolerance traits were measured at the individual level. To measure genetically based variation in thermal tolerance, and to avoid confounding maternal effects and thermal acclimation in the original environment, collected populations should be reared for at least one generation in the lab before experimentation. However, plasticity itself can be measured by, for example, varying larval rearing temperature (Dodson et al. 2012) or measuring thermoregulatory behavior as the trait of interest (e.g., Logan et al. 2018). Common garden experiments can also be used to measure the environmental sensitivity of selection if fitness is measured in addition to thermal tolerance traits (Chevin et al. 2010). Lastly, by tracking parentage and measuring thermal tolerance traits, the heritability of thermal tolerance can be measured based on the slope of the trait values of parent and offspring (Falconer and Mackay 1996).

In addition to providing estimates of rescue model parameters, common garden experiments can be combined with genomic approaches to identify genetic variants associated with climate-adaptive traits (Kort et al. 2014, Villemereuil et al. 2016, Exposito-Alonso et al. 2019, Capblancq et al. 2020). In the closest example of this approach in mosquito populations, the hypothesized thermo-adaptive role of a particular genotype (chromosomal inversion 2La) associated with aridity clines in Africa in An. gambiae (Coluzzi et al. 1979) was confirmed based on thermal tolerance experiments on the two genotypes (homokaryotypic populations $2 \mathrm{La}+$ and 2La) (Rocca et al. 2009). In other taxa, common garden experiments have been combined with genome scans to quantify and predict climate-driven selection along the genome of the plantArabidopsis thaliana (Exposito-Alonso et al. 2019), and to identify 162 candidate genes underlying climate adaptation in the harlequin fly Chironomus riparius (Waldvogel et al. 2018). In these studies, whole-genome sequencing would provide greater power to detect causal loci, thus this approach would be most feasible for mosquito species with available reference genomes, namely Ae. aegypti (e.g., Nene et al. 2007, Matthews et al. 2018), Ae. albopictus (Chen et al. 2015), An. darlingi (Marinotti et al. 2013), An. gambiae (Holt et al. 2002), and An. stephensi(Jiang et al. 2014).

Selection experiments and common garden experiments provide the means to obtain critical missing information on mosquito adaptive potential, but there are several challenges to these approaches. For any experimental test of adaptive potential, regardless of the methodology used, one must identify appropriate temperature treatments and pick fitness-relevant mosquito life history traits for which to assess thermal tolerance. Arbitrary choices for these details make it more difficult to extrapolate from these results to natural systems. Experiments commonly use treatments with constant temperatures above mean ambient temperatures. However, temperature minima or maxima, seasonal variability, and/or accumulated thermal stress may be more relevant to adaptive potential. For example, increases in minimum temperatures affect overnight recovery from heat stress in mosquitoes (Murdock et al. 2012, Bai et al. 2019). Further, given trade-offs in isolating the effect of temperature versus incorporating realistic ecological variation and in maximizing replication between versus within populations, no single study can definitively determine a species' adaptive potential. As a first step, controlled and replicated lab studies measuring mosquito fitness (either directly or as a composite of individual life history traits) under realistic projected thermal regimes that incorporate natural diurnal variation in temperature, combined with genomics approaches, will greatly improve our understanding on current and potential mosquito thermal adaptation (Andriamifidy et al. 2019). Such studies will inform parameters of evolutionary rescue models and, more broadly, enable investigation of the dynamics and limits of thermal adaptation.

\section{Discussion}

Accurate predictions of mosquito-borne disease distributions under climate change require reckoning with the potential for mosquitoes to adapt to rising temperatures. Estimating this potential is challenging, however, because thermal tolerance is a complex trait, mosquito vectors vary in their current thermal sensitivity, and many aspects of climate regimes are projected to change. Here, we have outlined a framework for investigating mosquito adaptive potential that involves identifying the climate factors and mosquito traits currently limiting persistence, then comparing the projected rates of environmental change to potential evolutionary rates in these traits using a simple evolutionary model (Chevin et al. 2010). This approach makes clear 
that some aspects of mosquito demographics and strong temperature-imposed selection may facilitate rapid evolution and adaptation. However, missing information on the heritability and within-population variation of thermal tolerance, the environmental sensitivity of selection, and the role of phenotypic plasticity (particularly behavioral thermoregulation), constrains our ability to make predictions about mosquito persistence and adaptation under climate warming. Common garden and selection experiments can be used to fill these data gaps but require careful consideration of the most relevant temperature treatments and mosquito life history traits.

In addition to the important data gaps we have emphasized within the evolutionary rescue framework, the model itself (Chevin et al. 2010) has several important limitations. Notably, these include the lack of potential genotype-by-environment interactions in the expression of phenotypes, evolution in plasticity, gene flow, genetic correlations between traits associated with thermal tolerance, and demographic or environmental stochasticity (Chevin et al. 2010). These simplifying assumptions make the model tractable but may limit the accuracy of the predictions if these factors play a large role in adaptation. Adding complexity would require additional data collection and may make predictive models too computationally intensive to solve analytically but can be implemented through simulations (Bürger and Lynch 1995). Several studies have effectively used simulations to incorporate environmental stochasticity (Ashander et al. 2016), demographic stochasticity (Martin et al. 2013), dispersal (Schiffers et al. 2013), carrying capacity (Bridle et al. 2010), and evolution in plasticity (Scheiner et al. 2017) into an evolutionary rescue model framework. Simulation results can be used to investigate transient evolutionary dynamics and can be compared with analytic results to determine the impact of these processes on evolutionary rescue. For example, Ashander et al. 2016 estimated population extinction risk using both analytic approximations and simulations to find that evolving plasticity only facilitated evolutionary rescue when the environmental change was sufficiently predictable. Using simulation to model more realistically complex evolutionary scenarios will likely be necessary when more precise forecasting is a priority, and is becoming a more approachable method through the availability of evolutionary simulation tools such as SLiM (Haller and Messer 2017).

Given the potential for thermal adaptation in the form of physiological changes in the thermal tolerance of mosquito life history traits, we now consider the potential implications for disease transmission. Mosquito thermal niche shifts could maintain, increase, or decrease disease transmission depending on whether evolved increases in thermal tolerance are accompanied by shifts in lower thermal limits, on the strength of thermodynamic constraints, and on genetic correlations between traits. In the absence of other changes to thermal performance, upward shifts in thermal limits could maintain current levels of disease transmission under rising temperatures, particularly if lower temperatures are infrequently experienced. However, disease transmission may increase if peak performances for mosquito traits like fecundity and biting rate increase with their thermal optima. This is an expectation of the "hotter-is-better" hypothesis, but how the shape of thermal performance curves evolves is a point of ongoing debate and empirical uncertainty (Angilletta et al. 2010, Latimer et al. 2011, Kontopoulos et al. 2020). Regardless, genetic correlations between mosquito traits under direct selection and other traits that may impact disease transmission (e.g., development time and immunocompetence, as observed in Ae. aegypti ; Koella and Boëte 2002) could still constrain mosquito-borne disease transmission under thermal adaptation (Lande and Arnold 1983).

Mosquitoes, like other ectotherms, may cope with warming temperatures through a variety of other mechanisms besides shifts in thermal physiology, such as accelerated life cycles, phenological shifts, and behavioral thermoregulation, with varying consequences for disease transmission (Huey and Kingsolver 1993, Bradshaw et al. 2000, Stearns et al. 2000, Angilletta et al. 2003, Waldvogel et al. 2020). Evolved increases in life cycle speed can mitigate increases in daily mortality rates, and were suggested to occur in Anopheles spp. in response to vector control interventions (Ferguson et al. 2012). As adult mosquito longevity is already the main limitation on transmission near upper thermal limits for many major mosquito-borne diseases (Mordecai et al. 2019), further reductions could cause large declines in transmission for pathogens with longer incubation periods. In particular, transmission of malaria parasites, which have a minimum incubation period of approximately nine days (Paaijmans et al. 2012, Blanford et al. 2013), may be more negatively impacted under this strategy than viral pathogens, such as dengue virus and chikungunya virus, which have generally faster 
incubation periods - as low as three to five days at temperatures above $30^{\circ} \mathrm{C}$ (Tjaden et al. 2013, Rudolph et al. 2014, Mordecai et al. 2019, Winokur et al. 2020). The implications of warming-driven life cycle adaptation therefore depend on the interaction between vector and pathogen traits, which vary across species and environments.

Behavioral thermoregulation and phenological shifts could increase, maintain, or decrease disease transmission, primarily depending on how these shifts impact mosquito - human contact rates and the effectiveness of vector control activities (Ferreira et al. 2017). For example, if rising temperatures promote shifts in biting activity towards the cooler, night-time hours when humans are more likely to be protected by bed nets, disease transmission may be reduced (Taylor 1975, Pates and Curtis 2005, Moiroux et al. 2012, Thomsen et al. 2017, Carrasco et al. 2019). However, in the absence of vector control, shifts towards night-time biting, as well as thermoregulatory shifts favoring indoor versus outdoor biting, could increase mosquito - human contact rates and transmission (Takken 2002). Similarly, phenological shifts in mosquito activity could lead to changes in the length or timing of disease transmission, potentially maintaining, increasing, or decreasing disease transmission. For example, increasing monthly mean temperatures in portions of California have effectively doubled the potential transmission season of St. Louis encephalitis virus, such that elderly persons traveling to California for the winter are newly at risk (Patz and Reisen 2001). Failing to account for phenological shifts in mosquito activity may render vector control programs less effective at reducing mosquito populations and disease transmission. In general, the impact of mosquito thermal adaptation on disease transmission will vary based on the mechanism of thermal adaptation, making identifying what adaptive strategies are most likely in different contexts a priority for future research.

Ultimately, how mosquitoes will adapt to climate change may depend on context-specific information (e.g., local human water storage practices that affect breeding habitat availability), additional evolutionary factors (e.g., rates of gene flow), and other ecological changes (e.g., land use change). Further, estimating the resulting effects on mosquito-borne disease distributions requires considering other mosquito adaptive mechanisms, eco-evolutionary responses of pathogens (Weaver 2006, Tabachnick 2016, Powell 2019), and climate effects on human immunology, behavior, and biogeography (reviewed in Reiter 2001, Patz and Reisen 2001, Sutherst 2004, Gage et al. 2008). This level of complexity can make the task of investigating mosquito climate adaptation daunting. However, the simple framework outlined here can be used to identify the mosquito species, geographic regions, and/or climate scenarios under which climate adaptation is more or less plausible. Targeted data collection efforts to address the key gaps outlined above will enable increasingly precise estimates of the probability of adaptation under different scenarios.

Many taxa that threaten human health and well-being share properties with mosquitoes that favor the potential for climate adaptation, such as short generation times, high population growth rates, and strong climate sensitivity. These include vectors of major human, wildlife, and plant disease (e.g., species of tsetse flies, biting midges, psyllids, and aphids), as well as pests of crops and forest resources (e.g., species of beetles, moths, fruit flies, and fire ants). Despite the substantial societal cost adaptation in pest and disease vector species could impose, their potential to adapt to climate change remains poorly understood. This remains challenging to predict given the many determinants of evolutionary rates, incomplete data on these determinants for most taxa, and the inability to perform a single, conclusive experiment. Drawing from conservation biology techniques used to study climate adaptive potentials in threatened and endangered species, we have outlined a framework and empirical approaches for investigating mosquito thermal adaptation that can be applied to any vector or pest species and type of environmental change. Combining available information on key components of evolutionary potential, leveraging information from related taxa where applicable, and using empirical approaches such as common garden or selection experiments to obtain multiple pieces of missing information at once will enable better estimates of adaptive potential. Understanding and estimating the potential for climate adaptation in taxa of concern to human health is critical for accurately predicting and preparing for their persistence or shifts in their distributions under climate change.

Acknowledgements

We thank George Somero for enlightening discussions about the molecular mechanisms of thermal tolerance. 
We thank Nina Dennington for sharing insight on experimental methods for studying mosquito thermal adaptation. We are grateful to Chris Anderson, Tejas Athni, Alex Becker, Caroline Glidden, and Morgan Kain for helpful feedback on the manuscript. EAM, DGK, JEF, and EBS were funded by the NIH National Institute of General Medical Sciences R35 MIRA program (R35GM133439). EAM, JEF, and MSS were funded by the NSF Ecology and Evolution of Infectious Diseases (EEID) program (DEB-1518681). EAM was funded by the NSF EEID program (DEB-2011147, with support from the Fogarty International Center), a Terman Award, and a Stanford King Center for Global Development seed grant. MLC was supported by the Illich-Sadowsky Fellowship through the Stanford Interdisciplinary Graduate Fellowship program. NN was supported by the Stanford Data Science Scholarship. LIC was funded by the Stanford Graduate Fellowship. JEF was funded by the Bing-Mooney Graduate Fellowship. MJH was funded by the Knight-Hennessy Scholarship.

\section{References}

1. Adamou, A., A. Dao, S. Timbine, Y. Kassogué, A. Yaro, M. Diallo, S. F. Traoré, D. L. Huestis, and T. Lehmann. 2011. The contribution of aestivating mosquitoes to the persistence of Anopheles gambiae in the Sahel. Malaria Journal 10:151.

2. Alto, B. W., and S. A. Juliano. 2001. Precipitation and Temperature Effects on Populations of Aedes albopictus (Diptera: Culicidae): Implications for Range Expansion. Journal of Medical Entomology 38:646-656.

3. Amarasekare, P., and V. Savage. 2012. A Framework for Elucidating the Temperature Dependence of Fitness. The American Naturalist 179:178-191.

4. Andriamifidy, R. F., N. B. Tjaden, C. Beierkuhnlein, and S. M. Thomas. 2019. Do we know how mosquito disease vectors will respond to climate change? Emerging Topics in Life Sciences 3:115-132.

5. Angilletta, M. J. 2009. Thermal Adaptation: A Theoretical and Empirical Synthesis. OUP Oxford.

6. Angilletta, M. J., R. B. Huey, and M. R. Frazier. 2010. Thermodynamic Effects on Organismal Performance: Is Hotter Better? Physiological and Biochemical Zoology 83:197-206.

7. Angilletta, M. J., R. S. Wilson, C. A. Navas, and R. S. James. 2003. Tradeoffs and the evolution of thermal reaction norms. Trends in Ecology \& Evolution 18:234-240.

8. Armbruster, P., W. E. Bradshaw, A. L. Steiner, and C. M. Holzapfel. 1999. Evolutionary responses to environmental stress by the pitcher-plant mosquito, Wyeomyia smithii. Heredity 83:509-519.

9. Ashander, J., L.-M. Chevin, and M. L. Baskett. 2016. Predicting evolutionary rescue via evolving plasticity in stochastic environments. Proceedings of the Royal Society B: Biological Sciences 283:20161690.

10. Ashburner, M. 1989. Drosophila. A laboratory handbook. Cold Spring Harbor Laboratory Press, Cold Spring Harbor, New york.

11. Bai, C.-M., G. Ma, W.-Z. Cai, and C.-S. Ma. 2019. Independent and combined effects of daytime heat stress and night-time recovery determine thermal performance. Biology Open 8.

12. Balanyá, J., J. M. Oller, R. B. Huey, G. W. Gilchrist, and L. Serra. 2006. Global Genetic Change Tracks Global Climate Warming in Drosophila subobscura. Science 313:1773-1775.

13. Barghi, N., R. Tobler, V. Nolte, A. M. Jakšić, F. Mallard, K. A. Otte, M. Dolezal, T. Taus, R. Kofler, and C. Schlötterer. 2019. Genetic redundancy fuels polygenic adaptation in Drosophila. PLOS Biology $17: \mathrm{e} 3000128$.

14. Barrera, R., M. Amador, A. Diaz, J. Smith, J. L. Munoz-Jordan, and Y. Rosario. 2008. Unusual productivity of Aedes aegypti in septic tanks and its implications for dengue control. Medical and Veterinary Entomology 22:62-69.

15. Bay, R. A., N. Rose, R. Barrett, L. Bernatchez, C. K. Ghalambor, J. R. Lasky, R. B. Brem, S. R. Palumbi, and P. Ralph. 2017. Predicting Responses to Contemporary Environmental Change Using Evolutionary Response Architectures. The American Naturalist 189:463-473.

16. Bell, G. 2017. Evolutionary Rescue. Annual Review of Ecology, Evolution, and Systematics 48:605627.

17. Bell, G., and A. Gonzalez. 2009. Evolutionary rescue can prevent extinction following environmental change. Ecology Letters 12:942-948.

18. Benedict, M. Q., A. F. Cockburn, and J. A. Seawright. 1991. Heat-shock mortality and induced 
thermotolerance in larvae of the mosquito Anopheles albimanus. Journal of the American Mosquito Control Association 7:5.

19. Berend, K., K. Haynes, and C. M. MacKenzie. 2019. Common garden experiments as a dynamic tool for ecology studies of alpine plants and communities in Northeastern North America. Rhodora 121:174.

20. Berrigan, D., and A. A. Hoffmann. 1998. Correlations between measures of heat resistance and acclimation in two species of Drosophila and their hybrids. Biological Journal of the Linnean Society 64:449-462.

21. Blanford, J. I., S. Blanford, R. G. Crane, M. E. Mann, K. P. Paaijmans, K. V. Schreiber, and M. B. Thomas. 2013. Implications of temperature variation for malaria parasite development across Africa. Scientific Reports 3:1300.

22. Bozinovic, F., D. A. Bastias, F. Boher, S. Clavijo-Baquet, S. A. Estay, and M. J. Angilletta. 2011. The Mean and Variance of Environmental Temperature Interact to Determine Physiological Tolerance and Fitness. Physiological and Biochemical Zoology 84:543-552.

23. Bradshaw, W. E., S. Fujiyama, and C. M. Holzapfel. 2000. Adaptation to the Thermal Climate of North America by the Pitcher-Plant Mosquito, Wyeomyia Smithii. Ecology 81:1262-1272.

24. Bradshaw, W. E., and C. M. Holzapfel. 2001. Genetic shift in photoperiodic response correlated with global warming. Proceedings of the National Academy of Sciences 98:14509-14511.

25. Brady, O. J., M. A. Johansson, C. A. Guerra, S. Bhatt, N. Golding, D. M. Pigott, H. Delatte, M. G. Grech, P. T. Leisnham, R. Maciel-de-Freitas, L. M. Styer, D. L. Smith, T. W. Scott, P. W. Gething, and S. I. Hay. 2013. Modelling adult Aedes aegypti and Aedes albopictus survival at different temperatures in laboratory and field settings. Parasites \& Vectors 6:351.

26. Bridle, J. R., J. Polechova, M. Kawata, and R. K. Butlin. 2010. Why is adaptation prevented at ecological margins? New insights from individual-based simulations. Ecology Letters 13:485-494.

27. Buckley, L. B., and R. B. Huey. 2016. How Extreme Temperatures Impact Organisms and the Evolution of their Thermal Tolerance. Integrative and Comparative Biology 56:98-109.

28. Burger, R., and M. Lynch. 1995. Evolution and Extinction in a Changing Environment: A Quantitative-Genetic Analysis. Evolution 49:151-163.

29. Capblancq, T., M. C. Fitzpatrick, R. A. Bay, M. Exposito-Alonso, and S. R. Keller. 2020. Genomic Prediction of (Mal)Adaptation Across Current and Future Climatic Landscapes. Annual Review of Ecology, Evolution, and Systematics 51:annurev-ecolsys-020720-042553.

30. Carlson, S. M., C. J. Cunningham, and P. A. H. Westley. 2014. Evolutionary rescue in a changing world. Trends in Ecology \& Evolution 29:521-530.

31. Carrasco, D., T. Lefevre, N. Moiroux, C. Pennetier, F. Chandre, and A. Cohuet. 2019. Behavioural adaptations of mosquito vectors to insecticide control. Current Opinion in Insect Science 34:48-54.

32. Carroll, S. P., A. P. Hendry, D. N. Reznick, and C. W. Fox. 2007. Evolution on ecological time-scales. Functional Ecology 21:387-393.

33. Castaneda, L. E., J. Balanya, E. L. Rezende, and M. Santos. 2013. Vanishing Chromosomal Inversion Clines in Drosophila subobscura from Chile: Is Behavioral Thermoregulation to Blame? The American Naturalist 182:249-259.

34. Castaneda, L. E., V. Romero-Soriano, A. Mesas, D. A. Roff, and M. Santos. 2019. Evolutionary potential of thermal preference and heat tolerance in Drosophila subobscura. Journal of Evolutionary Biology 32:818-824.

35. Cator, L. J., L. R. Johnson, E. A. Mordecai, F. El Moustaid, T. R. C. Smallwood, S. L. LaDeau, M. A. Johansson, P. J. Hudson, M. Boots, M. B. Thomas, A. G. Power, and S. Pawar. 2020. The Role of Vector Trait Variation in Vector-Borne Disease Dynamics. Frontiers in Ecology and Evolution 8:189.

36. Chadee, D. D., and R. Martinez. 2016. Aedes aegypti (L.) in Latin American and Caribbean region: With growing evidence for vector adaptation to climate change? Acta Tropica 156:137-143.

37. Chen, X.-G., X. Jiang, J. Gu, M. Xu, Y. Wu, Y. Deng, C. Zhang, M. Bonizzoni, W. Dermauw, J. Vontas, P. Armbruster, X. Huang, Y. Yang, H. Zhang, W. He, H. Peng, Y. Liu, K. Wu, J. Chen, M. Lirakis, P. Topalis, T. Van Leeuwen, A. B. Hall, X. Jiang, C. Thorpe, R. L. Mueller, C. Sun, R. M. Waterhouse, G. Yan, Z. J. Tu, X. Fang, and A. A. James. 2015. Genome sequence of the Asian Tiger 
mosquito, Aedes albopictus, reveals insights into its biology, genetics, and evolution. Proceedings of the National Academy of Sciences 112:E5907-E5915.

38. Chevin, L.-M., S. Collins, and F. Lefevre. 2013. Phenotypic plasticity and evolutionary demographic responses to climate change: taking theory out to the field. Functional Ecology 27:967-979.

39. Chevin, L.-M., R. Lande, and G. M. Mace. 2010. Adaptation, Plasticity, and Extinction in a Changing Environment: Towards a Predictive Theory. PLoS Biology 8.

40. Chevin, L.-M., M. E. Visser, and J. Tufto. 2015. Estimating the variation, autocorrelation, and environmental sensitivity of phenotypic selection. Evolution 69:2319-2332.

41. Chiang, H. C., and A. C. Hodson. 1950. An Analytical Study of Population Growth in Drosophila melanogaster. Ecological Monographs 20:173-206.

42. Chown, S. L., K. R. Jumbam, J. G. Sorensen, and J. S. Terblanche. 2009. Phenotypic variance, plasticity and heritability estimates of critical thermal limits depend on methodological context. Functional Ecology 23:133-140.

43. Christophers, S. R. 1960. Aedes aegypti (L.), the yellow fever mosquito. Cambridge University Press, Cambridge, UK.

44. Chu, V. M., M. a. M. Sallum, T. E. Moore, W. Lainhart, C. D. Schlichting, and J. E. Conn. 2019. Regional variation in life history traits and plastic responses to temperature of the major malaria vector Nyssorhynchus darlingi in Brazil. Scientific Reports 9:5356.

45. Clausen, J., D. D. Keck, and W. M. Hiesey. 1941. Regional Differentiation in Plant Species. The American Naturalist 75:231-250.

46. Collins, M., R. Knutti, J. Arblaster, J.-L. Dufresne, T. Fichefet, X. Gao, W. J. G. Jr, T. Johns, G. Krinner, M. Shongwe, A. J. Weaver, and M. Wehner. 2013. Long-term Climate Change: Projections, Commitments and Irreversibility. Page 108 Climate Change 2013: The Physical Science Basis. Contribution of Working Group I to the Fifth Assessment Report of the Intergovernmental Panel on Climate Change. Cambridge University Press, United Kingdom and New York.

47. Coluzzi, M., A. Sabatini, V. Petrarca, and M. A. Di Deco. 1979. Chromosomal differentiation and adaptation to human environments in the Anopheles gambiae complex. Transactions of The Royal Society of Tropical Medicine and Hygiene 73:483-497.

48. Cotto, O., J. Wessely, D. Georges, G. Klonner, M. Schmid, S. Dullinger, W. Thuiller, and F. Guillaume. 2017. A dynamic eco-evolutionary model predicts slow response of alpine plants to climate warming. Nature Communications 8.

49. Crow, J. F., and Y. J. Chung. 1967. Measurement of Effective Generation Length in Drosophila Population Cages. Genetics 57:951-955.

50. Dao, A., A. S. Yaro, M. Diallo, S. Timbine, D. L. Huestis, Y. Kassogue, A. I. Traore, Z. L. Sanogo, D. Samake, and T. Lehmann. 2014. Signatures of aestivation and migration in Sahelian malaria mosquito populations. Nature 516:387-390.

51. Delatte, H., G. Gimonneau, A. Triboire, and D. Fontenille. 2009. Influence of Temperature on Immature Development, Survival, Longevity, Fecundity, and Gonotrophic Cycles of Aedes albopictus, Vector of Chikungunya and Dengue in the Indian Ocean. Journal of Medical Entomology 46:33-41.

52. Deutsch, C. A., J. J. Tewksbury, R. B. Huey, K. S. Sheldon, C. K. Ghalambor, D. C. Haak, and P. R. Martin. 2008. Impacts of climate warming on terrestrial ectotherms across latitude. Proceedings of the National Academy of Sciences 105:6668-6672.

53. DeWitt, T. J., A. Sih, and D. S. Wilson. 1998. Costs and limits of phenotypic plasticity 13:5.

54. Diamond, S. E. 2017. Evolutionary potential of upper thermal tolerance: biogeographic patterns and expectations under climate change: Biogeography of evolutionary potential. Annals of the New York Academy of Sciences 1389:5-19.

55. Dillon, M. E., G. Wang, P. A. Garrity, and R. B. Huey. 2009. Thermal preference in Drosophila. Journal of Thermal Biology 34:109-119.

56. Diniz, D. F. A., C. M. R. de Albuquerque, L. O. Oliva, M. A. V. de Melo-Santos, and C. F. J. Ayres. 2017. Diapause and quiescence: dormancy mechanisms that contribute to the geographical expansion of mosquitoes and their evolutionary success. Parasites \& Vectors 10. 
57. Diniz-Filho, J. A. F., K. S. Souza, L. M. Bini, R. Loyola, R. Dobrovolski, J. F. M. Rodrigues, S. Lima-Ribeiro, L. C. Terribile, T. F. Rangel, I. Bione, R. Freitas, I. F. Machado, T. Rocha, M. L. Lorini, M. M. Vale, C. A. Navas, N. M. Maciel, F. Villalobos, M. A. Olalla-Tarraga, and S. Gouveia. 2019. A macroecological approach to evolutionary rescue and adaptation to climate change. Ecography 42:1124-1141.

58. Dodson, B. L., L. D. Kramer, and J. L. Rasgon. 2012. Effects of larval rearing temperature on immature development and West Nile virus vector competence of Culex tarsalis. Parasites \& Vectors 5:199.

59. Dowd, W. W., F. A. King, and M. W. Denny. 2015. Thermal variation, thermal extremes and the physiological performance of individuals. Journal of Experimental Biology 218:1956-1967.

60. Egizi, A., N. H. Fefferman, and D. M. Fonseca. 2015. Evidence that implicit assumptions of 'no evolution' of disease vectors in changing environments can be violated on a rapid timescale. Philosophical Transactions of the Royal Society B: Biological Sciences 370:20140136.

61. Emiljanowicz, L. M., G. D. Ryan, A. Langille, and J. Newman. 2014. Development, Reproductive Output and Population Growth of the Fruit Fly Pest Drosophila suzukii (Diptera: Drosophilidae) on Artificial Diet. Journal of Economic Entomology 107:1392-1398.

62. Exposito-Alonso, M., O. Bossdorf, R. Nielsen, and D. Weigel. 2019. Natural selection on the Arabidopsis thaliana genome in present and future climates. Nature 573:126-129.

63. Exposito-Alonso, M., F. Vasseur, W. Ding, G. Wang, H. A. Burbano, and D. Weigel. 2018. Genomic basis and evolutionary potential for extreme drought adaptation in Arabidopsis thaliana. Nature Ecology \& Evolution 2:352-358.

64. Falconer, D. S., and T. Mackay. 1996. Introduction to quantitative genetics. John Wiley and Sons, New York.

65. Fallis, L. C., J. J. Fanara, and T. J. Morgan. 2011. Genetic variation in heat-stress tolerance among South American Drosophila populations. Genetica 139:1331-1337.

66. Feder, M. E., N. Blair, and H. Figueras. 1997. Oviposition site selection: unresponsiveness of Drosophilato cues of potential thermal stress. Animal Behaviour 53:585-588.

67. Ferguson, H. M., N. Maire, W. Takken, I. N. Lyimo, O. Briet, S. W. Lindsay, and T. A. Smith. 2012. Selection of mosquito life-histories: a hidden weapon against malaria? Malaria Journal 11.

68. Fernandez-Moreno, M. A., C. L. Farr, L. S. Kaguni, and R. Garesse. 2007. Drosophila melanogaster as a Model System to Study Mitochondrial Biology. Methods in molecular biology (Clifton, N.J.) 372:33-49.

69. Ferreira, C. P., S. P. Lyra, F. Azevedo, D. Greenhalgh, and E. Massad. 2017. Modelling the impact of the long-term use of insecticide-treated bed nets on Anopheles mosquito biting time. Malaria Journal $16: 373$.

70. Focks, D. A., D. G. Haile, E. Daniels, and G. A. Mount. 1993. Dynamic Life Table Model for Aedes aegypti (Diptera: Culicidae): Analysis of the Literature and Model Development. Journal of Medical Entomology 30:1003-1017.

71. Franklinos, L. H. V., K. E. Jones, D. W. Redding, and I. Abubakar. 2019. The effect of global change on mosquito-borne disease. The Lancet Infectious Diseases 19:e302-e312.

72. Franks, S. J., S. Sim, and A. E. Weis. 2007. Rapid evolution of flowering time by an annual plant in response to a climate fluctuation. Proceedings of the National Academy of Sciences 104:1278-1282.

73. Fuller, R. C., C. F. Baer, and J. Travis. 2005. How and When Selection Experiments Might Actually be Useful. Integrative and Comparative Biology 45:391-404.

74. Gage, K. L., T. R. Burkot, R. J. Eisen, and E. B. Hayes. 2008. Climate and Vectorborne Diseases. American Journal of Preventive Medicine 35:436-450.

75. Garland, T., and M. R. Rose, editors. 2009. Experimental evolution: concepts, methods, and applications of selection experiments. University of California Press, Berkeley.

76. Gething, P. W., D. L. Smith, A. P. Patil, A. J. Tatem, R. W. Snow, and S. I. Hay. 2010. Climate change and the global malaria recession. Nature 465:342-345.

77. Gibbs, A. G., M. C. Perkins, and T. A. Markow. 2003. No place to hide: microclimates of Sonoran 
Desert Drosophila. Journal of Thermal Biology 28:353-362.

78. Gienapp, P., R. Leimu, and J. Merila. 2007. Responses to climate change in avian migration time-microevolution versus phenotypic plasticity. Climate Research 35:25-35.

79. Gienapp, P., M. Lof, T. E. Reed, J. McNamara, S. Verhulst, and M. E. Visser. 2013. Predicting demographically sustainable rates of adaptation: can great tit breeding time keep pace with climate change? Philosophical Transactions of the Royal Society B: Biological Sciences 368:20120289.

80. Gienapp, P., C. Teplitsky, J. S. Alho, J. A. Mills, and J. Merila. 2008. Climate change and evolution: disentangling environmental and genetic responses. Molecular Ecology 17:167-178.

81. Gomulkiewicz, R., and D. Houle. 2009. Demographic and Genetic Constraints on Evolution. The American Naturalist 174:E218-E229.

82. Gomulkiewicz, R., and R. G. Shaw. 2013. Evolutionary rescue beyond the models. Philosophical Transactions of the Royal Society B: Biological Sciences 368.

83. Gonzalez, A., O. Ronce, R. Ferriere, and M. E. Hochberg. 2013. Evolutionary rescue: an emerging focus at the intersection between ecology and evolution. Philosophical Transactions of the Royal Society B: Biological Sciences 368:20120404.

84. Gray, E. M. 2013. Thermal acclimation in a complex life cycle: The effects of larval and adult thermal conditions on metabolic rate and heat resistance in Culex pipiens (Diptera: Culicidae). Journal of Insect Physiology 59:1001-1007.

85. Gunderson, A. R., and J. H. Stillman. 2015. Plasticity in thermal tolerance has limited potential to buffer ectotherms from global warming. Proceedings of the Royal Society B: Biological Sciences 282:20150401.

86. Hairston, N. G., S. P. Ellner, M. A. Geber, T. Yoshida, and J. A. Fox. 2005. Rapid evolution and the convergence of ecological and evolutionary time. Ecology Letters 8:1114-1127.

87. Haller, B. C., and P. W. Messer. 2017. SLiM 2: Flexible, Interactive Forward Genetic Simulations. Molecular Biology and Evolution 34:230-240.

88. Hangartner, S., and A. A. Hoffmann. 2016. Evolutionary potential of multiple measures of upper thermal tolerance in Drosophila melanogaster. Functional Ecology:442-452.

89. Hartl, D. L., and A. G. Clark. 1997. Principles of Population Genetics, Fourth Edition. Sinauer Associates, Sunderland, MA.

90. van Heerwaarden, B., V. Kellermann, and C. M. Sgro. 2016. Limited scope for plasticity to increase upper thermal limits. Functional Ecology:1947-1956.

91. Hoffmann, A. A., A. Anderson, and R. Hallas. 2002. Opposing clines for high and low temperature resistance in Drosophila melanogaster. Ecology Letters 5:614-618.

92. Hoffmann, A. A., S. L. Chown, and S. Clusella-Trullas. 2013. Upper thermal limits in terrestrial ectotherms: how constrained are they? Functional Ecology 27:934-949.

93. Hoffmann, A. A., and C. M. Sgro. 2011. Climate change and evolutionary adaptation. Nature 470:479-485.

94. Hoffmann, A. A., and M. Watson. 1993. Geographical Variation in the Acclimation Responses of Drosophila to Temperature Extremes. The American Naturalist 142:S93-S113.

95. Holt, R. A., G. M. Subramanian, A. Halpern, G. G. Sutton, R. Charlab, D. R. Nusskern, P. Wincker, A. G. Clark, JoseM. C. Ribeiro, R. Wides, S. L. Salzberg, B. Loftus, M. Yandell, W. H. Majoros, D. B. Rusch, Z. Lai, C. L. Kraft, J. F. Abril, V. Anthouard, P. Arensburger, P. W. Atkinson, H. Baden, V. de Berardinis, D. Baldwin, V. Benes, J. Biedler, C. Blass, R. Bolanos, D. Boscus, M. Barnstead, S. Cai, A. Center, K. Chatuverdi, G. K. Christophides, M. A. Chrystal, M. Clamp, A. Cravchik, V. Curwen, A. Dana, A. Delcher, I. Dew, C. A. Evans, M. Flanigan, A. Grundschober-Freimoser, L. Friedli, Z. Gu, P. Guan, R. Guigo, M. E. Hillenmeyer, S. L. Hladun, J. R. Hogan, Y. S. Hong, J. Hoover, O. Jaillon, Z. Ke, C. Kodira, E. Kokoza, A. Koutsos, I. Letunic, A. Levitsky, Y. Liang, J.-J. Lin, N. F. Lobo, J. R. Lopez, J. A. Malek, T. C. McIntosh, S. Meister, J. Miller, C. Mobarry, E. Mongin, S. D. Murphy, D. A. O'Brochta, C. Pfannkoch, R. Qi, M. A. Regier, K. Remington, H. Shao, M. V. Sharakhova, C. D. Sitter, J. Shetty, T. J. Smith, R. Strong, J. Sun, D. Thomasova, L. Q. Ton, P. Topalis, Z. Tu, M. F. Unger, B. Walenz, A. Wang, J. Wang, M. Wang, X. Wang, K. J. Woodford, J. R. Wortman, M. 
Wu, A. Yao, E. M. Zdobnov, H. Zhang, Q. Zhao, S. Zhao, S. C. Zhu, I. Zhimulev, M. Coluzzi, A. della Torre, C. W. Roth, C. Louis, F. Kalush, R. J. Mural, E. W. Myers, M. D. Adams, H. O. Smith, S. Broder, M. J. Gardner, C. M. Fraser, E. Birney, P. Bork, P. T. Brey, J. C. Venter, J. Weissenbach, F. C. Kafatos, F. H. Collins, and S. L. Hoffman. 2002. The Genome Sequence of the Malaria Mosquito Anopheles gambiae. Science 298:129-149.

96. Huey, R. B., and D. Berrigan. 2001. Temperature, Demography, and Ectotherm Fitness.:7.

97. Huey, R. B., W. D. Crill, J. G. Kingsolver, and K. E. Weber. 1992. A Method for Rapid Measurement of Heat or Cold Resistance of Small Insects. Functional Ecology 6:489.

98. Huey, R. B., and J. G. Kingsolver. 1993. Evolution of Resistance to High Temperature in Ectotherms. The American Naturalist 142:S21-S46.

99. Huey, R. B., and J. G. Kingsolver. 2019. Climate Warming, Resource Availability, and the Metabolic Meltdown of Ectotherms. The American Naturalist 194:E140-E150.

100. Huey, R. B., L. Partridge, and K. Fowler. 1991. Thermal Sensitivity of Drosophila melanogaster Responds Rapidly to Laboratory Natural Selection. Evolution 45:751-756.

101. Huey, R. B., and M. Pascual. 2009. Partial thermoregulatory compensation by a rapidly evolving invasive species along a latitudinal cline. Ecology 90:1715-1720.

102. Huey, R. B., and R. D. Stevenson. 1979. Integrating Thermal Physiology and Ecology of Ectotherms: A Discussion of Approaches. American Zoologist 19:357-366.

103. IPCC. 2007. Climate Change 2007: The Physical Science Basis. Working Group I Contribution to the Fourth Assessment Report of the IPCC. Cambridge University Press, Cambridge, UK.

104. Jenkins, N. L., and A. Hoffmann. 1994. Genetic and Maternal Variationfor Heat Resistance in Drosophila from the Field. Genetics:783-389.

105. Jiang, X., A. Peery, A. B. Hall, A. Sharma, X.-G. Chen, R. M. Waterhouse, A. Komissarov, M. M. Riehle, Y. Shouche, M. V. Sharakhova, D. Lawson, N. Pakpour, P. Arensburger, V. L. M. Davidson, K. Eiglmeier, S. Emrich, P. George, R. C. Kennedy, S. P. Mane, G. Maslen, C. Oringanje, Y. Qi, R. Settlage, M. Tojo, J. M. C. Tubio, M. F. Unger, B. Wang, K. D. Vernick, J. M. C. Ribeiro, A. A. James, K. Michel, M. A. Riehle, S. Luckhart, I. V. Sharakhov, and Z. Tu. 2014. Genome analysis of a major urban malaria vector mosquito, Anopheles stephensi:18.

106. Johnson, L. R., T. Ben-Horin, K. D. Lafferty, A. McNally, E. Mordecai, K. P. Paaijmans, S. Pawar, and S. J. Ryan. 2015. Understanding uncertainty in temperature effects on vector-borne disease: a Bayesian approach. Ecology 96:203-213.

107. Joubert, D. A., T. Walker, L. B. Carrington, J. T. D. Bruyne, D. H. T. Kien, N. L. T. Hoang, N. V. V. Chau, I. Iturbe-Ormaetxe, C. P. Simmons, and S. L. O'Neill. 2016. Establishment of a Wolbachia Superinfection in Aedes aegypti Mosquitoes as a Potential Approach for Future Resistance Management. PLOS Pathogens 12:e1005434.

108. Kamimura, K., I. Matsuse, H. Takahashi, T. Fukudai, K. Suzukii, M. Aratanii, Y. Shiraii, and M. Mogi. 2002. Effect of temperature on the development of Aedes aegppti and Aedes albopictus. The Japan Society of Medical Entomology and Zoology 53:53-58.

109. Karell, P., K. Ahola, T. Karstinen, J. Valkama, and J. E. Brommer. 2011. Climate change drives microevolution in a wild bird. Nature Communications 2:1-7.

110. Kauffman, E., A. Payne, M. Franke, M. Schmid, E. Harris, and L. Kramer. 2017. Rearing of Culex spp. and Aedes spp. Mosquitoes. BIO-PROTOCOL 7.

111. Kearney, M., W. P. Porter, C. Williams, S. Ritchie, and A. A. Hoffmann. 2009. Integrating biophysical models and evolutionary theory to predict climatic impacts on species' ranges: the dengue mosquito Aedes aegypti in Australia. Functional Ecology 23:528-538.

112. Kellermann, V., J. Overgaard, A. A. Hoffmann, C. Flojgaard, J.-C. Svenning, and V. Loeschcke. 2012. Upper thermal limits of Drosophila are linked to species distributions and strongly constrained phylogenetically. Proceedings of the National Academy of Sciences 109:16228-16233.

113. Kingsolver, J. G., S. E. Diamond, and L. B. Buckley. 2013. Heat stress and the fitness consequences of climate change for terrestrial ectotherms. Functional Ecology 27:1415-1423.

114. Koella, J. C., and C. Boete. 2002. A Genetic Correlation Between Age at Pupation and Melanization 
Immune Response of the Yellow Fever Mosquito Aedes Aegypti. Evolution 56:1074-1079.

115. Kontopoulos, D.-G., E. van Sebille, M. Lange, G. Yvon-Durocher, T. G. Barraclough, and S. Pawar. 2020. Phytoplankton thermal responses adapt in the absence of hard thermodynamic constraints. Evolution 74:775-790.

116. Kort, H. D., K. Vandepitte, H. H. Bruun, D. Closset-Kopp, O. Honnay, and J. Mergeay. 2014. Landscape genomics and a common garden trial reveal adaptive differentiation to temperature across Europe in the tree species Alnus glutinosa. Molecular Ecology 23:4709-4721.

117. Kovach, R. P., A. J. Gharrett, and D. A. Tallmon. 2012. Genetic change for earlier migration timing in a pink salmon population. Proceedings of the Royal Society B: Biological Sciences 279:3870-3878.

118. Lambrechts, L., K. P. Paaijmans, T. Fansiri, L. B. Carrington, L. D. Kramer, M. B. Thomas, and T. W. Scott. 2011. Impact of daily temperature fluctuations on dengue virus transmission by Aedes aegypti. Proceedings of the National Academy of Sciences 108:7460-7465.

119. Lande, R. 1976. Natural Selection and Random Genetic Drift in Phenotypic Evolution. Evolution 30:314-334.

120. Lande, R., and S. J. Arnold. 1983. The Measurement of Selection on Correlated Characters. Evolution $37: 1210-1226$.

121. Latimer, C. a. L., R. S. Wilson, and S. F. Chenoweth. 2011. Quantitative genetic variation for thermal performance curves within and among natural populations of Drosophila serrata. Journal of Evolutionary Biology 24:965-975.

122. Lavergne, S., N. Mouquet, W. Thuiller, and O. Ronce. 2010. Biodiversity and Climate Change: Integrating Evolutionary and Ecological Responses of Species and Communities. Annual Review of Ecology, Evolution, and Systematics 41:321-350.

123. Le Goff, G., D. Damiens, A.-H. Ruttee, L. Payet, C. Lebon, J.-S. Dehecq, and L.-C. Gouagna. 2019. Field evaluation of seasonal trends in relative population sizes and dispersal pattern of Aedes albopictus males in support of the design of a sterile male release strategy. Parasites \& Vectors 12:81.

124. Lehmann, T., A. Dao, A. S. Yaro, A. Adamou, Y. Kassogue, M. Diallo, T. Sekou, and C. CoscaronArias. 2010. Aestivation of the African Malaria Mosquito, Anopheles gambiae in the Sahel. The American Journal of Tropical Medicine and Hygiene 83:601-606.

125. Lehmann, T., A. Dao, A. S. Yaro, M. Diallo, S. Timbine, D. L. Huestis, A. Adamou, Y. Kassogue, and A. I. Traore. 2014. Seasonal Variation in Spatial Distributions of Anopheles gambiae in a Sahelian Village: Evidence for Aestivation. Journal of Medical Entomology 51:27-38.

126. Lehmann, T., W. A. Hawley, H. Grebert, and F. H. Collins. 1998. The effective population size of Anopheles gambiae in Kenya: implications for population structure. Molecular Biology and Evolution 15:264-276.

127. Lin, Q.-C., Y.-F. Zhai, A.-S. Zhang, X.-Y. Men, X.-Y. Zhang, F. G. Zalom, C.-G. Zhou, and Y. Yu. 2014. Comparative developmental times and laboratory life tables for Drosophila suzukii and Drosophila melanogaster (Diptera: Drosophilidae). The Florida Entomologist 97:1434-1442.

128. Lockwood, B. L., T. Gupta, and R. Scavotto. 2018. Disparate patterns of thermal adaptation between life stages in temperate vs. tropical Drosophila melanogaster. Journal of Evolutionary Biology 31:323331.

129. Loeschcke, V., and A. Hoffmann. 2007. Consequences of Heat Hardening on a Field Fitness Component in Drosophila Depend on Environmental Temperature. The American Naturalist 169:175-183.

130. Logan, M. L., J. D. Curlis, A. L. Gilbert, D. B. Miles, A. K. Chung, J. W. McGlothlin, and R. M. Cox. 2018. Thermal physiology and thermoregulatory behaviour exhibit low heritability despite genetic divergence between lizard populations. Proceedings of the Royal Society B: Biological Sciences $285: 20180697$.

131. Lynch, M., and R. Lande. 1993. Evolution and extinction in response to environ mental change. Biotic Interactions and Global Change:234-250.

132. Lyons, C. L., M. Coetzee, J. S. Terblanche, and S. L. Chown. 2012. Thermal limits of wild and laboratory strains of two African malaria vector species, Anopheles arabiensis and Anopheles funestus. Malaria Journal 11:226. 
133. Macdonald, G. 1952. The Analysis of the Sporozoite Rate. Tropical Diseases Bulletin 49.

134. Maciel-de-Freitas, R., A. E. Eiras, and R. Lourenco-de-Oliveira. 2008. Calculating the survival rate and estimated population density of gravid Aedes aegypti (Diptera, Culicidae) in Rio de Janeiro, Brazil. Cadernos de Saude Publica 24:2747-2754.

135. MacLean, H. J., J. G. Sorensen, T. N. Kristensen, V. Loeschcke, K. Beedholm, V. Kellermann, and J. Overgaard. 2019. Evolution and plasticity of thermal performance: an analysis of variation in thermal tolerance and fitness in 22 Drosophila species. Philosophical Transactions of the Royal Society B: Biological Sciences 374:20180548.

136. Manda, H., L. M. Arce, T. Foggie, P. Shah, J. P. Grieco, and N. L. Achee. 2011. Effects of Irritant Chemicals on Aedes aegypti Resting Behavior: Is There a Simple Shift to Untreated "Safe Sites"? PLoS Neglected Tropical Diseases 5.

137. Marinotti, O., G. C. Cerqueira, L. G. P. de Almeida, M. I. T. Ferro, E. L. da S. Loreto, A. Zaha, S. M. R. Teixeira, A. R. Wespiser, A. Almeida e Silva, A. D. Schlindwein, A. C. L. Pacheco, A. L. da C. da Silva, B. R. Graveley, B. P. Walenz, B. de A. Lima, C. A. G. Ribeiro, C. G. Nunes-Silva, C. R. de Carvalho, C. M. de A. Soares, C. B. A. de Menezes, C. Matiolli, D. Caffrey, D. A. M. Araujo, D. M. de Oliveira, D. Golenbock, E. C. Grisard, F. Fantinatti-Garboggini, F. M. de Carvalho, F. G. Barcellos, F. Prosdocimi, G. May, G. M. de Azevedo Junior, G. M. Guimaraes, G. H. Goldman, I. Q. M. Padilha, J. da S. Batista, J. A. Ferro, J. M. C. Ribeiro, J. L. R. Fietto, K. M. Dabbas, L. Cerdeira, L. F. Agnez-Lima, M. Brocchi, M. O. de Carvalho, M. de M. Teixeira, M. de M. Diniz Maia, M. H. S. Goldman, M. P. Cruz Schneider, M. S. S. Felipe, M. Hungria, M. F. Nicolas, M. Pereira, M. A. Montes, M. E. Cantao, M. Vincentz, M. S. Rafael, N. Silverman, P. H. Stoco, R. C. Souza, R. Vicentini, R. T. Gazzinelli, R. de O. Neves, R. Silva, S. Astolfi-Filho, T. E. F. Maciel, T. P. Urmenyi, W. P. Tadei, E. P. Camargo, and A. T. R. de Vasconcelos. 2013. The Genome of Anopheles darlingi, the main neotropical malaria vector. Nucleic Acids Research 41:7387-7400.

138. Martin, G., R. Aguilee, J. Ramsayer, O. Kaltz, and O. Ronce. 2013. The probability of evolutionary rescue: towards a quantitative comparison between theory and evolution experiments. Philosophical Transactions of the Royal Society B: Biological Sciences 368:20120088.

139. Matsumura, S., R. Arlinghaus, and U. Dieckmann. 2012. Standardizing Selection Strengths to Study Selection in the Wild: A Critical Comparison and Suggestions for the Future. BioScience 62:1039-1054.

140. Matthews, B. J., O. Dudchenko, S. B. Kingan, S. Koren, I. Antoshechkin, J. E. Crawford, W. J. Glassford, M. Herre, S. N. Redmond, N. H. Rose, G. D. Weedall, Y. Wu, S. S. Batra, C. A. BritoSierra, S. D. Buckingham, C. L. Campbell, S. Chan, E. Cox, B. R. Evans, T. Fansiri, I. Filipović, A. Fontaine, A. Gloria-Soria, R. Hall, V. S. Joardar, A. K. Jones, R. G. G. Kay, V. K. Kodali, J. Lee, G. J. Lycett, S. N. Mitchell, J. Muehling, M. R. Murphy, A. D. Omer, F. A. Partridge, P. Peluso, A. P. Aiden, V. Ramasamy, G. Rašić, S. Roy, K. Saavedra-Rodriguez, S. Sharan, A. Sharma, M. L. Smith, J. Turner, A. M. Weakley, Z. Zhao, O. S. Akbari, W. C. Black, H. Cao, A. C. Darby, C. A. Hill, J. S. Johnston, T. D. Murphy, A. S. Raikhel, D. B. Sattelle, I. V. Sharakhov, B. J. White, L. Zhao, E. L. Aiden, R. S. Mann, L. Lambrechts, J. R. Powell, M. V. Sharakhova, Z. Tu, H. M. Robertson, C. S. McBride, A. R. Hastie, J. Korlach, D. E. Neafsey, A. M. Phillippy, and L. B. Vosshall. 2018. Improved reference genome of Aedes aegypti informs arbovirus vector control. Nature 563:501-507.

141. McColl, G., A. A. Hoffmann, and S. McKechnie. 1996. Response of Two Heat Shock Genes to Selection for Knockdown Heat Resistance in Drosophila melanogaster | Genetics 143:1615-1627.

142. Medley, K. A. 2010. Niche shifts during the global invasion of the Asian tiger mosquito, Aedes albopictus Skuse (Culicidae), revealed by reciprocal distribution models. Global Ecology and Biogeography 19:122-133.

143. Medley, K. A., K. M. Westby, and D. G. Jenkins. 2019. Rapid local adaptation to northern winters in the invasive Asian tiger mosquito Aedes albopictus: A moving target. Journal of Applied Ecology $56: 2518-2527$.

144. Merilä, J., and A. P. Hendry. 2014. Climate change, adaptation, and phenotypic plasticity: the problem and the evidence. Evolutionary Applications 7:1-14.

145. Mitchell, K. A., and A. A. Hoffmann. 2010. Thermal ramping rate influences evolutionary potential 
and species differences for upper thermal limits in Drosophila: Limited $h^{2}$ and reduced thermal limits in Drosophila. Functional Ecology 24:694-700.

146. Mogi, M. 1992. Temperature and Photoperiod Effects on Larval and Ovarian Development of New Zealand Strains of Culex quinquefasciatus (Diptera: Culicidae). Annals of the Entomological Society of America 85:58-66.

147. Moiroux, N., M. B. Gomez, C. Pennetier, E. Elanga, A. Djènontin, F. Chandre, I. Djègbé, H. Guis, and V. Corbel. 2012. Changes in Anopheles funestus Biting Behavior Following Universal Coverage of Long-Lasting Insecticidal Nets in Benin. The Journal of Infectious Diseases 206:1622-1629.

148. Mordecai, E. A., J. M. Caldwell, M. K. Grossman, C. A. Lippi, L. R. Johnson, M. Neira, J. R. Rohr, S. J. Ryan, V. Savage, M. S. Shocket, R. Sippy, A. M. S. Ibarra, M. B. Thomas, and O. Villena. 2019. Thermal biology of mosquito-borne disease. Ecology Letters 22:1690-1708.

149. Mordecai, E. A., J. M. Cohen, M. V. Evans, P. Gudapati, L. R. Johnson, C. A. Lippi, K. Miazgowicz, C. C. Murdock, J. R. Rohr, S. J. Ryan, V. Savage, M. S. Shocket, A. S. Ibarra, M. B. Thomas, and D. P. Weikel. 2017. Detecting the impact of temperature on transmission of Zika, dengue, and chikungunya using mechanistic models. PLOS Neglected Tropical Diseases 11:e0005568.

150. Mordecai, E. A., S. J. Ryan, J. M. Caldwell, M. M. Shah, and A. D. LaBeaud. 2020. Climate change could shift disease burden from malaria to arboviruses in Africa. The Lancet Planetary Health 4:e416e423.

151. Mousseau, T. A., and D. A. Roff. 1987. Natural selection and the heritability of fitness components. Heredity 59:181-197.

152. Mueller, L. D., and F. J. Ayala. 1981. Trade-off between r-selection and K-selection in Drosophila populations. Proceedings of the National Academy of Sciences 78:1303-1305.

153. Munstermann, L. E. 1997. Care and maintenance of Aedes mosquito colonies. Pages 13-20 in J. M. Crampton, C. B. Beard, and C. Louis, editors. The Molecular Biology of Insect Disease Vectors: A Methods Manual. Springer Netherlands, Dordrecht.

154. Murdock, C. C., K. P. Paaijmans, A. S. Bell, J. G. King, J. F. Hillyer, A. F. Read, and M. B. Thomas. 2012. Complex effects of temperature on mosquito immune function. Proceedings of the Royal Society B: Biological Sciences 279:3357-3366.

155. Muturi, E. J., R. Lampman, K. Costanzo, and B. W. Alto. 2011. Effect of Temperature and Insecticide Stress on Life-History Traits of Culex restuans and Aedes albopictus (Diptera: Culicidae). Journal of Medical Entomology 48:243-250.

156. Nayar, J. K., and D. M. Sauerlllan. 1971. The effects of diet on life-span, fecundity and flight potential of Aedes taeniorhynchus adults. Journal of Medical Entomology 8:8.

157. Neira, M., R. Lacroix, L. Cáceres, P. E. Kaiser, J. Young, L. Pineda, I. Black, N. Sosa, D. Nimmo, L. Alphey, and A. McKemey. 2014. Estimation of Aedes aegypti (Diptera: Culicidae) population size and adult male survival in an urban area in Panama. Memórias do Instituto Oswaldo Cruz 109:879-886.

158. Nene, V., J. R. Wortman, D. Lawson, B. Haas, C. Kodira, Z. (Jake) Tu, B. Loftus, Z. Xi, K. Megy, M. Grabherr, Q. Ren, E. M. Zdobnov, N. F. Lobo, K. S. Campbell, S. E. Brown, M. F. Bonaldo, J. Zhu, S. P. Sinkins, D. G. Hogenkamp, P. Amedeo, P. Arensburger, P. W. Atkinson, S. Bidwell, J. Biedler, E. Birney, R. V. Bruggner, J. Costas, M. R. Coy, J. Crabtree, M. Crawford, B. deBruyn, D. DeCaprio, K. Eiglmeier, E. Eisenstadt, H. El-Dorry, W. M. Gelbart, S. L. Gomes, M. Hammond, L. I. Hannick, J. R. Hogan, M. H. Holmes, D. Jaffe, J. S. Johnston, R. C. Kennedy, H. Koo, S. Kravitz, E. V. Kriventseva, D. Kulp, K. LaButti, E. Lee, S. Li, D. D. Lovin, C. Mao, E. Mauceli, C. F. M. Menck, J. R. Miller, P. Montgomery, A. Mori, A. L. Nascimento, H. F. Naveira, C. Nusbaum, S. O'Leary, J. Orvis, M. Pertea, H. Quesneville, K. R. Reidenbach, Y.-H. Rogers, C. W. Roth, J. R. Schneider, M. Schatz, M. Shumway, M. Stanke, E. O. Stinson, J. M. C. Tubio, J. P. VanZee, S. Verjovski-Almeida, D. Werner, O. White, S. Wyder, Q. Zeng, Q. Zhao, Y. Zhao, C. A. Hill, A. S. Raikhel, M. B. Soares, D. L. Knudson, N. H. Lee, J. Galagan, S. L. Salzberg, I. T. Paulsen, G. Dimopoulos, F. H. Collins, B. Birren, C. M. Fraser-Liggett, and D. W. Severson. 2007. Genome Sequence of Aedes aegypti, a Major Arbovirus Vector. Science 316:1718-1723.

159. Nussey, D. H., E. Postma, P. Gienapp, and M. E. Visser. 2005. Selection on Heritable Phenotypic 
Plasticity in a Wild Bird Population. Science 310:304-306.

160. Orr, H. A., and R. L. Unckless. 2008. Population Extinction and the Genetics of Adaptation. The American Naturalist 172:160-169.

161. Overgaard, J., T. N. Kristensen, K. A. Mitchell, and A. A. Hoffmann. 2011. Thermal Tolerance in Widespread and Tropical Drosophila Species: Does Phenotypic Plasticity Increase with Latitude? The American Naturalist 178:S80-S96.

162. Ożgo, M., and M. Schilthuizen. 2012. Evolutionary change in Cepaea nemoralis shell colour over 43 years. Global Change Biology 18:74-81.

163. Paaijmans, K. P., S. Blanford, B. H. K. Chan, and M. B. Thomas. 2012. Warmer temperatures reduce the vectorial capacity of malaria mosquitoes. Biology Letters 8:465-468.

164. Paaijmans, K. P., R. L. Heinig, R. A. Seliga, J. I. Blanford, S. Blanford, C. C. Murdock, and M. B. Thomas. 2013. Temperature variation makes ectotherms more sensitive to climate change. Global Change Biology 19:2373-2380.

165. Paaijmans, K. P., and M. B. Thomas. 2011. The influence of mosquito resting behaviour and associated microclimate for malaria risk. Malaria Journal 10:1-7.

166. Papadopoulos, N. T., J. R. Carey, C. S. Ioannou, H. Ji, H.-G. Müller, J.-L. Wang, S. Luckhart, and E. E. Lewis. 2016. Seasonality of Post-capture Longevity in a Medically-Important Mosquito (Culex pipiens). Frontiers in Ecology and Evolution 4.

167. Pates, H., and C. Curtis. 2005. Mosquito Behavior and Vector Control. Annual Review of Entomology 50:53-70.

168. Patz, J. A., S. H. Olson, C. K. Uejio, and H. K. Gibbs. 2008. Disease Emergence from Global Climate and Land Use Change. Medical Clinics of North America 92:1473-1491.

169. Patz, J. A., and W. K. Reisen. 2001. Immunology, climate change and vector-borne diseases. Trends in Immunology 22:171-172.

170. Powell, J. R. 2019. An Evolutionary Perspective on Vector-Borne Diseases. Frontiers in Genetics 10.

171. Rashkovetsky, E., K. Iliadi, P. Michalak, A. Lupu, E. Nevo, M. E. Feder, and A. Korol. 2006. Adaptive differentiation of thermotolerance in Drosophila along a microclimatic gradient. Heredity 96:353-359.

172. Réale, D., A. G. McAdam, S. Boutin, and D. Berteaux. 2003. Genetic and plastic responses of a northern mammal to climate change. Proceedings of the Royal Society of London. Series B: Biological Sciences 270:591-596.

173. Reisen, W. 1995. Effect of Temperature on Culex tarsalis (Diptera: Culicidae) from the Coachella and San Joaquin Valleys of California. Journal of Medical Entomology 32:636-645.

174. Reisen, W. K., and M. Aslamkhan. 1978. Biting rhythms of some Pakistan mosquitoes (Diptera: Culicidae). Bulletin of Entomological Research 68:313-330.

175. Reiter, P. 2001. Climate change and mosquito-borne disease. Environmental Health Perspectives 109:21.

176. Rezende, E. L., F. Bozinovic, A. Szilágyi, and M. Santos. 2020. Predicting temperature mortality and selection in naturalDrosophila populations. Science 369:1242-1245.

177. Reznick, D. N., J. Losos, and J. Travis. 2019. From low to high gear: there has been a paradigm shift in our understanding of evolution. Ecology Letters 22:233-244.

178. Rocca, K. A., E. M. Gray, C. Costantini, and N. J. Besansky. 2009. 2La chromosomal inversion enhances thermal tolerance of Anopheles gambiae larvae. Malaria Journal 8:147.

179. Rocklöv, J., and R. Dubrow. 2020. Climate change: an enduring challenge for vector-borne disease prevention and control. Nature Immunology 21:479-483.

180. Rodríguez-Trelles, F., and M. A. Rodríguez. 1998. Rapid micro-evolution and loss of chromosomal diversity in Drosophila in response to climate warming. Evolutionary Ecology 12:829-838.

181. Roff, D. A., and T. A. Mousseau. 1987. Quantitative genetics and fitness: lessons from Drosophila. Heredity 58:103-118.

182. Rohr, J. R., D. J. Civitello, J. M. Cohen, E. A. Roznik, B. Sinervo, and A. I. Dell. 2018. The complex drivers of thermal acclimation and breadth in ectotherms. Ecology Letters 21:1425-1439.

183. Rolandi, C., J. R. B. Lighton, G. J. de la Vega, P. E. Schilman, and J. Mensch. 2018. Genetic variation for tolerance to high temperatures in a population of Drosophila melanogaster. Ecology and Evolution 
8:10374-10383.

184. Román-Palacios, C., and J. J. Wiens. 2020. Recent responses to climate change reveal the drivers of species extinction and survival. Proceedings of the National Academy of Sciences 117:4211-4217.

185. Rudolph, K. E., J. Lessler, R. M. Moloney, B. Kmush, and D. A. T. Cummings. 2014. Incubation Periods of Mosquito-Borne Viral Infections: A Systematic Review. The American Journal of Tropical Medicine and Hygiene 90:882-891.

186. Ruybal, J. E., L. D. Kramer, and A. M. Kilpatrick. 2016. Geographic variation in the response of Culex pipiens life history traits to temperature. Parasites \& Vectors 9:116.

187. Ryan, S. J., C. J. Carlson, E. A. Mordecai, and L. R. Johnson. 2019. Global expansion and redistribution of Aedes-borne virus transmission risk with climate change. PLOS Neglected Tropical Diseases 13:e0007213.

188. Ryan, S. J., A. McNally, L. R. Johnson, E. A. Mordecai, T. Ben-Horin, K. Paaijmans, and K. D. Lafferty. 2015. Mapping Physiological Suitability Limits for Malaria in Africa Under Climate Change. Vector-Borne and Zoonotic Diseases 15:718-725.

189. Scheiner, S. M., M. Barfield, and R. D. Holt. 2017. The genetics of phenotypic plasticity. XV. Genetic assimilation, the Baldwin effect, and evolutionary rescue. Ecology and Evolution 7:8788-8803.

190. Scheiner, S. M., and D. Berrigan. 1998. The Genetics of Phenotypic Plasticity. VIII. The Cost of Plasticity in Daphnia pulex. Evolution 52:368-378.

191. Schiffers, K., E. C. Bourne, S. Lavergne, W. Thuiller, and J. M. J. Travis. 2013. Limited evolutionary rescue of locally adapted populations facing climate change. Philosophical Transactions of the Royal Society B: Biological Sciences 368:20120083.

192. Sears, M. W., M. J. Angilletta, M. S. Schuler, J. Borchert, K. F. Dilliplane, M. Stegman, T. W. Rusch, and W. A. Mitchell. 2016. Configuration of the thermal landscape determines thermoregulatory performance of ectotherms. Proceedings of the National Academy of Sciences 113:10595-10600.

193. Sgrò, C. M., J. Overgaard, T. N. Kristensen, K. A. Mitchell, F. E. Cockerell, and A. A. Hoffmann. 2010. A comprehensive assessment of geographic variation in heat tolerance and hardening capacity in populations of Drosophila melanogaster from eastern Australia. Journal of Evolutionary Biology 23:2484-2493.

194. Shapiro, L. L. M., S. A. Whitehead, and M. B. Thomas. 2017. Quantifying the effects of temperature on mosquito and parasite traits that determine the transmission potential of human malaria. PLOS Biology 15:e2003489.

195. Shocket, M. S., S. J. Ryan, and E. A. Mordecai. 2018. Temperature explains broad patterns of Ross River virus transmission. eLife 7:e37762.

196. Shocket, M. S., A. B. Verwillow, M. G. Numazu, H. Slamani, J. M. Cohen, F. El Moustaid, J. Rohr, L. R. Johnson, and E. A. Mordecai. 2020. Transmission of West Nile and five other temperate mosquitoborne viruses peaks at temperatures between $23^{\circ} \mathrm{C}$ and $26^{\circ} \mathrm{C}$. eLife 9:e58511.

197. Shragai, T., B. Tesla, C. Murdock, and L. C. Harrington. 2017. Zika and chikungunya: mosquito-borne viruses in a changing world: Global change and vectors of chikungunya and Zika. Annals of the New York Academy of Sciences 1399:61-77.

198. Siddiqui, W. H., and C. A. Barlow. 1972. Population Growth of Drosophila melanogaster (Diptera: Drosophilidae) at Constant and Alternating Temperatures1. Annals of the Entomological Society of America 65:993-1001.

199. Sivan, A., A. N. Shriram, P. Vanamail, and A. P. Sugunan. 2020. Thermotolerance and acclimation in the immature stages of Aedes aegypti (L) (Diptera: Culicidae) to simulated thermal stress. International Journal of Tropical Insect Science.

200. Somero, G., B. Lockwood, and L. Tomanek. 2016. Temperature. Page 200 Biochemical Adaptation.

201. Somero, G. N. 1995. Proteins and Temperature. Annual Review of Physiology 57:43-68.

202. Somero, G. N. 2003. Protein adaptations to temperature and pressure: complementary roles of adaptive changes in amino acid sequence and internal milieu. Comparative Biochemistry and Physiology Part B: Biochemistry and Molecular Biology 136:577-591.

203. Somero, G. N. 2010. The physiology of climate change: how potentials for acclimatization and genetic 
adaptation will determine 'winners' and 'losers.' Journal of Experimental Biology 213:912-920.

204. Somers, G., J. E. Brown, R. Barrera, and J. R. Powell. 2011. Genetics and Morphology of Aedes aegypti (Diptera: Culicidae) in Septic Tanks in Puerto Rico. Journal of Medical Entomology 48:1095-1102.

205. Sørensen, J. G., J. Dahlgaard, and V. Loeschcke. 2001. Genetic variation in thermal tolerance among natural populations of Drosophila buzzatii: down regulation of Hsp70 expression and variation in heat stress resistance traits. Functional Ecology 15:289-296.

206. Sørensen, J. G., T. N. Kristensen, and J. Overgaard. 2016. Evolutionary and ecological patterns of thermal acclimation capacity in Drosophila: is it important for keeping up with climate change? Current Opinion in Insect Science 17:98-104.

207. Stearns, S. C., M. Ackermann, M. Doebeli, and M. Kaiser. 2000. Experimental evolution of aging, growth, and reproduction in fruitflies. Proceedings of the National Academy of Sciences 97:3309-3313.

208. Stinchcombe, J. R., L. A. Dorn, and J. Schmitt. 2004. Flowering time plasticity in Arabidopsis thaliana: a reanalysis of Westerman \& Lawrence (1970). Journal of Evolutionary Biology 17:197-207.

209. Sutherst, R. W. 2004. Global Change and Human Vulnerability to Vector-Borne Diseases. Clinical Microbiology Reviews 17:136-173.

210. Swallow, J., J. Hayes, P. Koteja, and T. Garland. 2009. Selection Experiments and Experimental Evolution of Performance and Physiology. Experimental Evolution: Concepts, Methods, and Applications of Selection Experiments.

211. Tabachnick, W. J. 2016. Ecological effects on arbovirus-mosquito cycles of transmission. Current Opinion in Virology 21:124-131.

212. Takken, W. 2002. Do insecticide-treated bednets have an effect on malaria vectors? Tropical Medicine \& International Health 7:1022-1030.

213. Tatar, M., S. A. Chien, and N. K. Priest. 2001. Negligible Senescence during Reproductive Dormancy in Drosophila melanogaster. The American Naturalist 158:248-258.

214. Taylor, B. 1975. Changes in the feeding behaviour of a malaria vector, Anopheles farauti Lav., following use of DDT as a residual spray in houses in the British Solomon Islands Protectorate. Transactions of the Royal Entomological Society of London 127:277-292.

215. Terblanche, J. S., J. A. Deere, S. Clusella-Trullas, C. Janion, and S. L. Chown. 2007. Critical thermal limits depend on methodological context. Proceedings of the Royal Society B: Biological Sciences 274:2935-2943.

216. Tesla, B., L. R. Demakovsky, E. A. Mordecai, S. J. Ryan, M. H. Bonds, C. N. Ngonghala, M. A. Brindley, and C. C. Murdock. 2018. Temperature drives Zika virus transmission: evidence from empirical and mathematical models. Proceedings of the Royal Society B: Biological Sciences.

217. Thompson, J. N. 1998. Rapid evolution as an ecological process. Trends in Ecology \& Evolution 13:329332 .

218. Thomsen, E. K., G. Koimbu, J. Pulford, S. Jamea-Maiasa, Y. Ura, J. B. Keven, P. M. Siba, I. Mueller, M. W. Hetzel, and L. J. Reimer. 2017. Mosquito Behavior Change After Distribution of Bednets Results in Decreased Protection Against Malaria Exposure. The Journal of Infectious Diseases 215:790-797.

219. Tjaden, N. B., S. M. Thomas, D. Fischer, and C. Beierkuhnlein. 2013. Extrinsic Incubation Period of Dengue: Knowledge, Backlog, and Applications of Temperature Dependence. PLoS Neglected Tropical Diseases 7:e2207.

220. Touré, Y. T., G. Dolo, V. Petrarca, Traoré, Bouaré, A. Dao, J. Carnahan, and C. E. Taylor. 1998. Markrelease-recapture experiments with Anopheles gambiae s.l. in Banambani Village, Mali, to determine population size and structure. Medical and Veterinary Entomology 12:74-83.

221. Umina, P. A., A. R. Weeks, M. R. Kearney, S. W. McKechnie, and A. A. Hoffmann. 2005. A Rapid Shift in a Classic Clinal Pattern in Drosophila Reflecting Climate Change. Science 308:691-693.

222. Urban, M. C., G. Bocedi, A. P. Hendry, J.-B. Mihoub, G. Peer, A. Singer, J. R. Bridle, L. G. Crozier, L. De Meester, W. Godsoe, A. Gonzalez, J. J. Hellmann, R. D. Holt, A. Huth, K. Johst, C. B. Krug, P. W. Leadley, S. C. F. Palmer, J. H. Pantel, A. Schmitz, P. A. Zollner, and J. M. J. Travis. 2016. Improving the forecast for biodiversity under climate change. Science 353:aad8466-aad8466.

223. Urbanski, J., M. Mogi, D. O’Donnell, M. DeCotiis, T. Toma, and P. Armbruster. 2012. Rapid Adaptive 
Evolution of Photoperiodic Response during Invasion and Range Expansion across a Climatic Gradient. The American Naturalist 179:490-500.

224. Vasseur, D. A., J. P. DeLong, B. Gilbert, H. S. Greig, C. D. G. Harley, K. S. McCann, V. Savage, T. D. Tunney, and M. I. O'Connor. 2014. Increased temperature variation poses a greater risk to species than climate warming. Proceedings of the Royal Society B: Biological Sciences 281:20132612.

225. Via, S., R. Gomulkiewicz, G. De Jong, S. M. Scheiner, C. D. Schlichting, and P. H. Van Tienderen. 1995. Adaptive phenotypic plasticity: consensus and controversy. Trends in Ecology \& Evolution 10:212-217.

226. Villemereuil, P., O. E. Gaggiotti, M. Mouterde, and I. Till-Bottraud. 2016. Common garden experiments in the genomic era: new perspectives and opportunities. Heredity 116:249-254.

227. Voorham, J. 2002. Intra-population plasticity of Anopheles darlingi's (Diptera, Culicidae) biting activity patterns in the state of Amapá, Brazil. Revista de Saúde Pública 36:75-80.

228. Vorhees, A. S., E. M. Gray, and T. J. Bradley. 2013. Thermal Resistance and Performance Correlate with Climate in Populations of a Widespread Mosquito. Physiological and Biochemical Zoology 86:7381.

229. Waldock, J., N. L. Chandra, J. Lelieveld, Y. Proestos, E. Michael, G. Christophides, and P. E. Parham. 2013. The role of environmental variables on Aedes albopictus biology and chikungunya epidemiology. Pathogens and Global Health 107:224-241.

230. Waldvogel, A.-M., B. Feldmeyer, G. Rolshausen, M. Exposito-Alonso, C. Rellstab, R. Kofler, T. Mock, K. Schmid, I. Schmitt, T. Bataillon, O. Savolainen, A. Bergland, T. Flatt, F. Guillaume, and M. Pfenninger. 2020. Evolutionary genomics can improve prediction of species' responses to climate change. Evolution Letters 4:4-18.

231. Waldvogel, A.-M., A. Wieser, T. Schell, S. Patel, H. Schmidt, T. Hankeln, B. Feldmeyer, and M. Pfenninger. 2018. The genomic footprint of climate adaptation in Chironomus riparius. Molecular Ecology 27:1439-1456.

232. Wang, G., T. N. Gordon, and S. Rainwater. 2008. Maximum voluntary temperature of insect larvae reveals differences in their thermal biology. Journal of Thermal Biology 33:380-384.

233. Weaver, S. C. 2006. Evolutionary Influences in Arboviral Disease. Pages 285-314 in E. Domingo, editor. Quasispecies: Concept and Implications for Virology. Springer, Berlin, Heidelberg.

234. West-Eberhard, M. J. 2003. Developmental Plasticity and Evolution. Oxford University Press.

235. Whitman, D., and A. Agrawal. 2009. What is Phenotypic Plasticity and Why is it Important? Page in D. Whitman and T. Ananthakrishnan, editors. Phenotypic Plasticity of Insects. Science Publishers.

236. Willi, Y., and A. A. Hoffmann. 2009. Demographic factors and genetic variation influence population persistence under environmental change. Journal of Evolutionary Biology 22:124-133.

237. Winokur, O. C., B. J. Main, J. Nicholson, and C. M. Barker. 2020. Impact of temperature on the extrinsic incubation period of Zika virus in Aedes aegypti. PLOS Neglected Tropical Diseases 14:e0008047.

238. World Health Organization. 2014. A global brief on vector-borne diseases. World Health Organization Technical Report.

239. World Health Organization. 2018. Global Vector Control Response 2017- 2030. World Health Organization.

240. Yang, H. M., M. L. G. Macoris, K. C. Galvani, M. T. M. Andrighetti, and D. M. V. Wanderley. 2009. Assessing the Effects of Temperature on the Population of Aedes aegypti, the Vector of Dengue. Epidemiology and Infection 137:1188-1202.

241. Yaro, A. S., A. I. Traore, D. L. Huestis, A. Adamou, S. Timbine, Y. Kassogue, M. Diallo, A. Dao, S. F. Traore, and T. Lehmann. 2012. Dry season reproductive depression of Anopheles gambiae in the Sahel. Journal of Insect Physiology 58:1050-1059.

\section{Box 1.}


Evolutionary rescue model formula (Chevin et al. 2010) and parameter definitions.

$$
\eta_{\mathrm{c}}=\sqrt{\frac{2 r_{\max } \gamma}{T}} \frac{h^{2} \sigma^{2}}{|B-b|}
$$

$\eta_{c}$ : maximum rate of environmental change: the highest rate of sustained environmental change under which long-term population persistence is possible.

$r_{\max }$ : maximum population growth rate: the intrinsic rate of increase under optimal conditions (i.e., no intra- or inter-specific competition).

$\gamma$ : strength of selection: the impact on fitness from deviations from the optimal trait value under a given environment. As in Kearney et al. 2009, a standardized version of selection strength can be approximated from temperature-dependent survival rates by:

$i=2.2014-0.04884 s+0.000558 s^{2}-0.0000029 s^{3}$

where $s$ is the percentage survival under a given environmental change, and $i$ is given as the change in phenotype (in standard deviations) between the starting and selected populations (Falconer and Mackay 1996, Matsumura et al. 2012).

T: population generation time : (for populations with discrete, non-overlapping generations), the mean time between reproduction in one cohort to reproduction in the successive cohort.

$h^{2}$ : heritability : the proportion of phenotypic variance in a trait attributable to additive genetic effects.

$\sigma^{2}$ : phenotypic variance : the measured variance in the trait of interest

B: environmental sensitivity of selection : the change in the optimum phenotype with environmental change.

b: phenotypic plasticity: the ability of individual genotypes to produce alternative phenotypes in different environments (Via et al. 1995). Here, plasticity encompasses thermal acclimation, dormancy and behavioral thermoregulation including shifts in mosquito biting, microhabitat usage, and oviposition sites and timing.

Figure Legends

\section{Figure 1.}

Framework for investigating mosquito climate adaptive potential. Several mechanisms may enable in situ population persistence (evolutionary adaptations in mosquito physiology, phenotypic plasticity, phenological shifts, and life history adjustments; top panel). Investigating the potential for evolutionary climate adaptation requires first identifying the climate factors and traits limiting population persistence (middle panel), then comparing the rate of projected climatic change to potential evolutionary rates (bottom panel). Evolutionary rates can be estimated based on evolutionary potential (strength of selection, and heritability and variation in the trait of interest), population demographic characteristics (maximum growth rate and generation time), and trait - environment relationships (phenotypic plasticity and environmental sensitivity of selection). In the strength of selection panel (top left), the dashed and solid lines indicate the population before and after natural selection, respectively. In the heritability panel (bottom left), P1 and F1 denote the parental and offspring generations.

\section{Figure 2.}

State of knowledge on evolutionary rescue model parameters for mosquito and Drosophila species. Numbers correspond to references; colors correspond to data availability. Purple indicates that data for these parameters are readily available (but not for all species or contexts). Blue indicates that some data are available, but further collection is warranted. Green indicates that minimal or indirect data are available 
(e.g., dormancy mechanisms suspected based on rapid mosquito population increases following the dry season). Yellow indicates that no estimates are available on these parameters (to our knowledge). Measurements on variation in thermal tolerance are designated as 'between-population' or 'within-population.'

Mechanisms enablingin situ population persistence

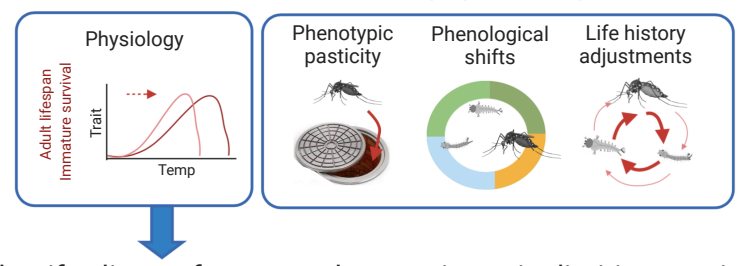

Identify climate factors and mosquito traits limiting persistence
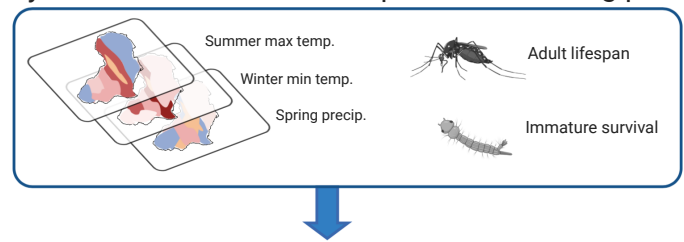

Compare rate of projected climate change to max evolutionary rates

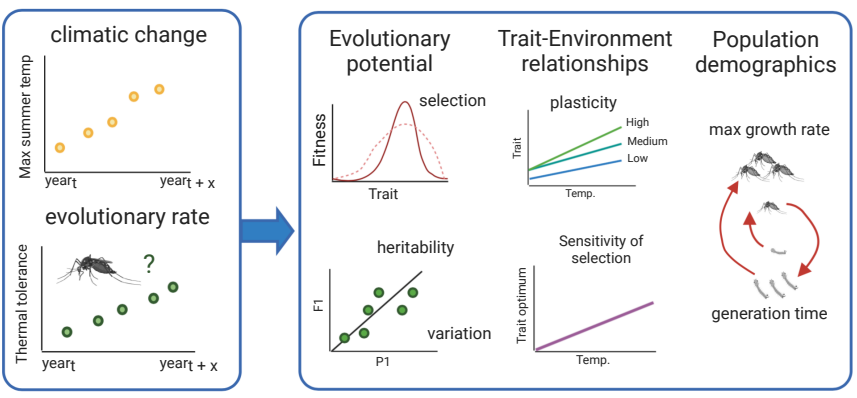




\begin{tabular}{|c|c|c|}
\hline $\begin{array}{l}\text { Available data } \\
\text { Some data }\end{array}$ & \multicolumn{2}{|c|}{ State of knowledge } \\
\hline No data & Mosquitoes & Drosophila \\
\hline Generation time & $106,149,196$ & $10,49,61,68,127$ \\
\hline $\begin{array}{l}\text { Maximum population } \\
\text { growth rate }\end{array}$ & $3,106,149,196$ & $41,61,152,198$ \\
\hline $\begin{array}{l}\text { Variation in thermal } \\
\text { tolerance }\end{array}$ & $\begin{array}{c}\text { [Between-population } \\
\text { variation] } \\
44,58,146,174,178 \\
186,228\end{array}$ & $\begin{array}{c}\text { [Within-population } \\
\text { variation] } \\
65,183 \\
\text { [Between-population } \\
\text { variation] } \\
91,128,171,193,205 \\
\end{array}$ \\
\hline Heritability & & $34,97,88,104,141,145$ \\
\hline Strength of selection & reviewed in 148 & $97,100,129,176$ \\
\hline Acclimation & $8,18,84,132,199$ & $20,94,135,161,193$ \\
\hline 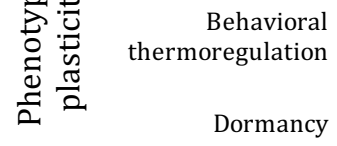 & $1,50,124,125,241$ & $\begin{array}{c}33,55,66,77,101,135, \\
232\end{array}$ \\
\hline $\begin{array}{c}\text { Environmental } \\
\text { sensitivity of selection }\end{array}$ & & \\
\hline
\end{tabular}

